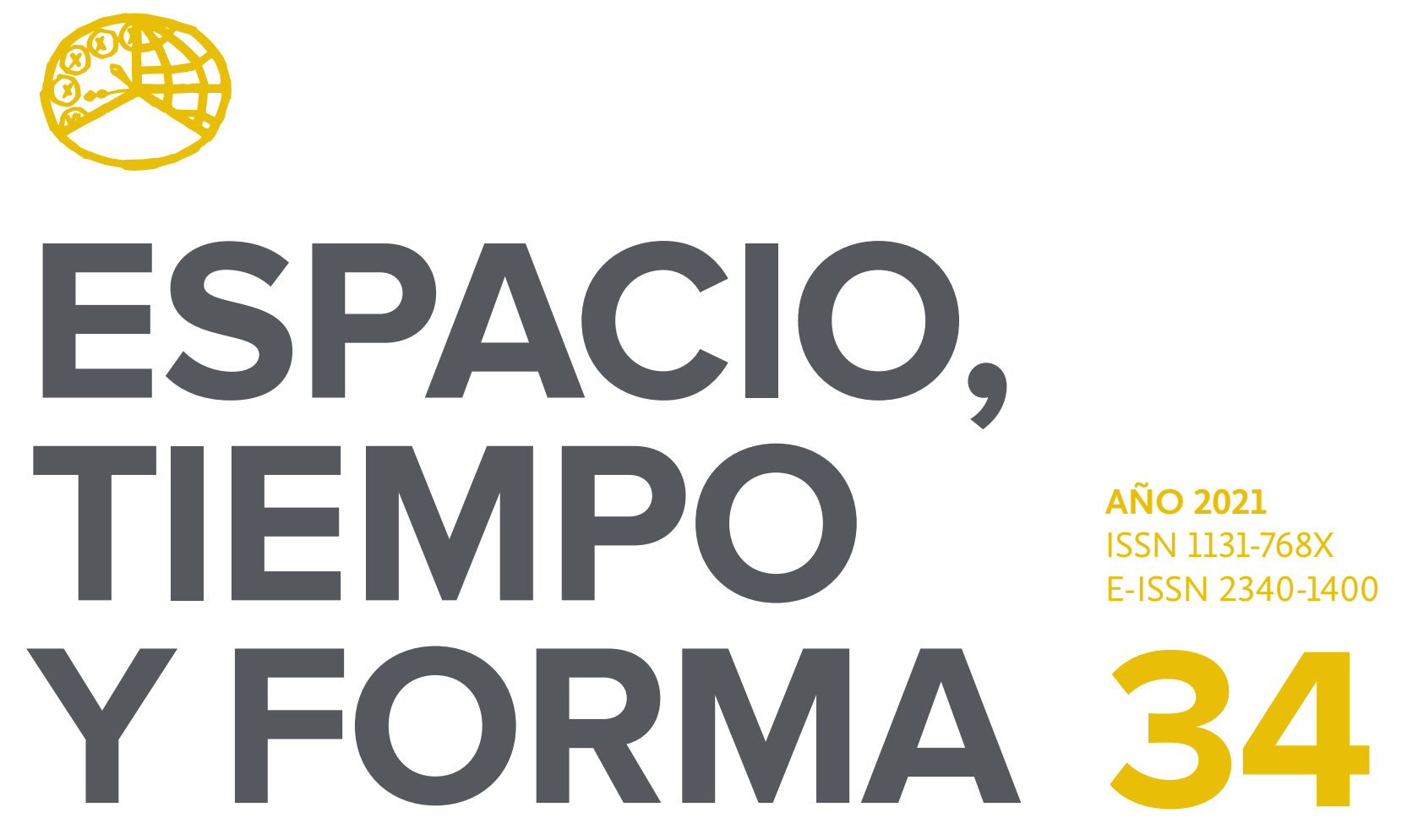

SERIE IV HISTORIA MODERNA

REVISTA DE LA FACULTAD DE GEOGRAFÍA E HISTORIA

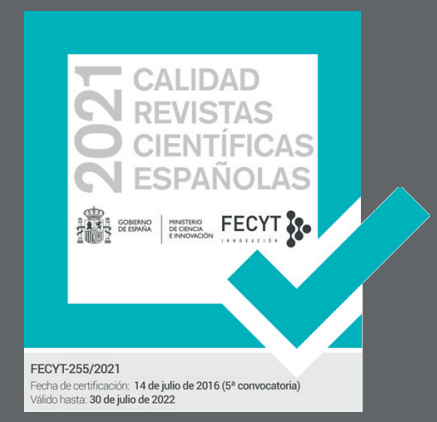




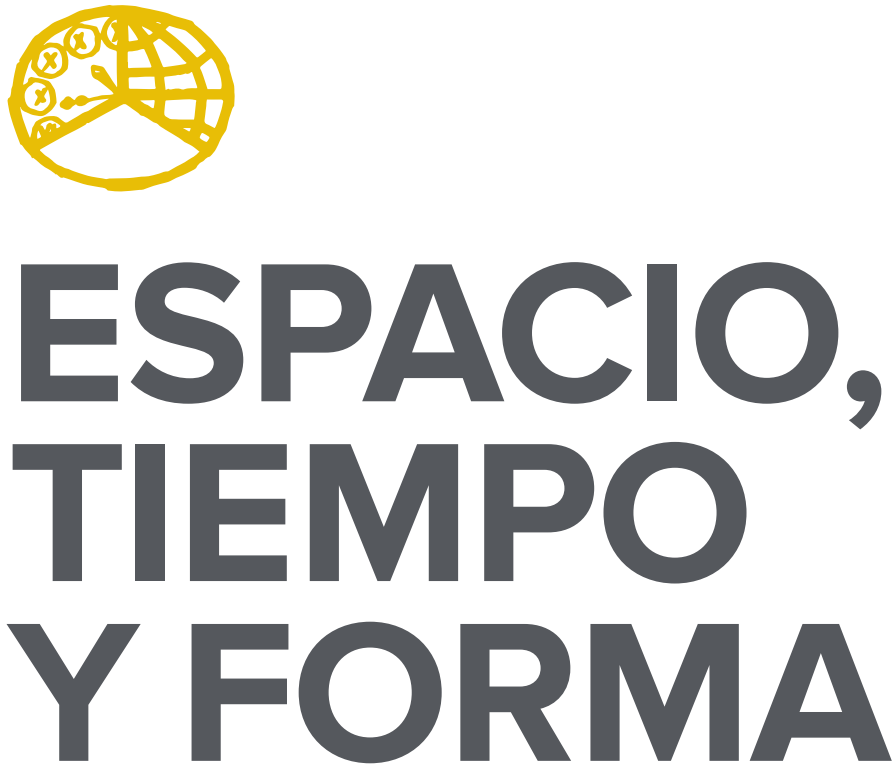

AÑO 2021

ISSN 1131-768X

E-ISSN 2340-1400

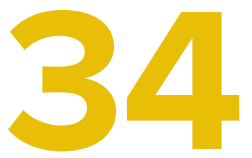

SERIE IV HISTORIA MODERNA

REVISTA DE LA FACULTAD DE GEOGRAFÍA E HISTORIA

DOI: https://doi.org/10.5944/etfiv.34.2021

\section{UกED}

UNIVERSIDAD NACIONAL DE EDUCACIÓN A DISTANCIA 
La revista Espacio, Tiempo y Forma (siglas recomendadas: ETF), de la Facultad de Geografía e Historia de la UNED, que inició su publicación el año 1988, está organizada de la siguiente forma:

$$
\begin{aligned}
& \text { SERIE I - Prehistoria y Arqueología } \\
& \text { SERIE II - Historia Antigua } \\
& \text { SERIE III - Historia Medieval } \\
& \text { SERIE IV - Historia Moderna } \\
& \text { SERIE V - Historia Contemporánea } \\
& \text { SERIE VI - Geografía } \\
& \text { SERIE VII - Historia del Arte }
\end{aligned}
$$

Excepcionalmente, algunos volúmenes del año 1988 atienden a la siguiente numeración:

$$
\begin{aligned}
& \mathrm{N} .^{\circ} 1 \text { - Historia Contemporánea } \\
& \mathrm{N}^{\circ} 2 \text { - Historia del Arte } \\
& \mathrm{N} .^{\circ} 3 \text { - Geografía } \\
& \mathrm{N} .^{\circ} 4 \text { - Historia Moderna }
\end{aligned}
$$

ETF no se solidariza necesariamente con las opiniones expresadas por los autores.

\author{
UNIVERSIDAD NACIONAL DE EDUCACIÓN A DISTANCIA \\ Madrid, 2021 \\ SERIE IV · HISTORIA MODERNA N. ${ }^{\circ} 34,2021$ \\ ISSN $1131-768 X \cdot$ E-ISSN 2340-1400 \\ DEPÓSITO LEGAL \\ M-21.037-1988 \\ URL \\ ETF IV · HISTORIA MODERNA · http://revistas.uned.es/index.php/ETFIV \\ DISEÑO Y COMPOSICIÓN \\ Carmen Chincoa Gallardo · http://www.laurisilva.net/cch \\ Impreso en España · Printed in Spain
}

(c) (7) (8) Esta obra está bajo una licencia Creative Commons Reconocimiento-NoComercial 4.0 Internacional. 


\section{MISCELÁNEA • MISCELLANY}





\title{
«SOLO EL TIEMPO NOS LAS DECLARARÁ \\ A TODOS»: EL PAPEL DE TAIWÁN \\ DENTRO DEL ORGANIGRAMA \\ COMERCIAL Y MILITAR DE LA \\ GOBERNACIÓN DE FILIPINAS DURANTE \\ LA PRIMERA MITAD DEL SIGLO XVII
}

\author{
"ONLY TIME WILL TELL US»: THE ROLE OF \\ TAIWAN WITHIN THE COMMERCIAL AND \\ MILITARY ORGANIZATION OF THE PHILIPPINE'S \\ GOVERNORATION DURING THE FIRST \\ HALF OF THE SEVENTEENTH CENTURY
}

José Miguel Herrera Reviriego ${ }^{1}$

Recibido: 22/04/2021 - Aceptado: 14/07/2021

DOI: https://doi.org/10.5944/etfiv.34.2021.30690

\begin{abstract}
Resumen
Para la Gobernación de Filipinas, la isla de Taiwán, supuso desde finales del siglo XVI una importante fuente de incertidumbre tanto en el ámbito comercial como militar, que acabaría provocando la conquista de su extremo norte en I626. Durante los siguientes años, la Monarquía se enfrentaría al reto de encajar esta nueva pieza en el entramado defensivo y económico preexistente. Pero diversos cambios acontecidos en el continente favorecieron que los planes iníciales para este territorio fueran desestimados. En este artículo, intentaremos aproximarnos al papel de jugó Taiwán en el Asia hispánica y como diversas alteraciones regionales acabaron por dejar a esta plaza sin atribuciones defensivas y comerciales propias.
\end{abstract}

Palabras clave

Taiwán; Filipinas; Comercio; Historia militar; China

Abstract

For the Government of the Philippines, the island of Taiwan represented an important source of uncertainty both in the commercial and military fields, which would

1. Universidad de Castellón Jaume I; herrera.reviriego@gmail.com

Este trabajo se enmarca en el proyecto «El sudeste asiático bajo la influencia ibérica en el mundo, 1581-1668» (PID2019-107430GB-loo), aprobado y financiado por el Ministerio de Ciencia e Innovación y la Agencia Nacional de Investigación. 
end up causing the conquest of its extreme north in I626. During the following years, the Monarchy was would face the challenge of fitting this new piece into the pre-existing defensive and economic framework. But various changes that occurred in the continent favored the initial plans for this territory to be rejected. In this article, we will try to get closer to the role of Taiwan in Hispanic Asia and how various regional alterations ended up leaving this place without its own defensive and commercial prerogatives.

Keywords

Taiwan; Philippines; Comerce; military history; China 
EL 22 DE ENERO DE 1637, y tras solo un año y medio en Filipinas, el gobernador Sebastián Hurtado de Corcuera, convocó una junta de guerra en la ciudad de Manila para analizar el estado de los presidios hispánicos en Asia. A ella acudieron algunos de los militares más importantes de cuantos se encontraban en el archipiélago, como Juan de Ezquerra o Alonso García Romero, así como los principales cargos públicos de la administración de la Gobernación, como el fiscal Juan Fernández de Ledo o el factor Iñigo de Villarreal. Los debates llevados a cabo en entre los asistentes, se centraron, principalmente, en la situación de los presidios de Zamboanga y de los del norte de Taiwán, y si los beneficios obtenidos en ellos compensaban los cuantiosos recursos y esfuerzos invertidos.

Realmente, y en contra de lo ocurrido en otras juntas, el presidente de la Audiencia filipina ya contaba con una opinión clara al respecto, antes siquiera de escuchar el parecer de los asistentes. Ya que, para él, algunos de los presidios hispánicos en Asia no resultaban rentables para los intereses de la Monarquía, o al menos, no lo eran tal y como se encontraban en estos momentos, incidiendo, sobre todo, en el caso de las fortalezas de San Salvador y Santo Domingo de Taiwán, aludiendo a que en estas: «Muchas de congruencia del servicio de su magestad, se an visto fustradas en el discurso de los dichos onçe años [de presencia en Taiwán] y solo a tenido efecto el grande gasto de su haçienda real $»^{2}$. Esta afirmación venía acompañada de un análisis de los desembolsos efectuados en los presidios de Formosa ${ }^{3}$, que alcanzaban la nada desdeñable cifra de I.300.0oo pesos, cantidad sumamente grande, sobre todo para una Gobernación, que en los últimos años empezaba a conocer unos problemas de liquidez que se volverían recurrentes durante gran parte del siglo XVII. Mientras que cifraba entre los 4.000 y los 5.000 pesos los beneficios obtenidos por la Corona por la estancia en esta isla ${ }^{4}$. Al mismo tiempo que remarcaba los problemas que habían encontrado las tropas hispánicas, ya no solo para expandir el territorio, sino para permanecer en el ya controlado. Así como, en las dificultades y lentos avances, que la Orden de Santo Domingo, había obtenido en la evangelización de los indígenas de la conocida por sus contemporáneos como Isla Hermosa. Por lo que concluiría que, tras once años de presencia hispánica y continuos esfuerzos y desembolsos por parte de la Corona, no se habían alcanzado ninguno de los objetivos por los que se había tomado la isla en I626.

Los presentes en la junta, compartieron la opinión de Sebastián Hurtado de Corcuera, a excepción del sargento mayor Alonso García Romero, quien tras haber servido en San Salvador como gobernador, solo apoyó un posible abandono de Zamboanga ${ }^{5}$. De modo que la gran mayoría de los reunidos, aludieron a que sería

\footnotetext{
2. Archivo General de Indias ( en adelante AGI), Filipinas 21, R.11, N.55. Junta de guerra sobre el estado de los presidios, Manila, 22/01/1637.

3. AGI, Filipinas 21, R.11, N.55. Informe de los gastos efectuados en la conquista y mantenimiento de los presidios de Taiwán, Manila, 1637 .

4. «Con que pudo interesar la hacienda de vuestra magestad de quatro a cinco mill pesos. Este es señor todo el provecho que Ysla Hermosa a dado a vuestra magestad en onze años o cerca de doce». AGl, Filipinas 21, R.11, N.55. Carta de Sebastián Hurtado de Corcuera, Manila, 20/08/1637.

5. «En lo tocante a la fuerça de Samboanga, es de pareçer se rretire luego, por quanto no se consigue el intento
} 
aconsejable retirar tanto los presidios de Taiwán como el del sur de Mindanao y utilizar las tropas y recursos destinados en ellos a reforzar la ciudad de Manila ${ }^{6}$.

De todos modos, y a pesar de tener el apoyo de los más importantes militares y miembros de la administración de las islas, el presidente de la Audiencia, no se atrevió a llevar a cabo el abandono de ninguna fortaleza de importancia, pues uno de los principales deberes de un gobernador, era el de mantener el territorio heredado. Además, la retirada voluntaria de una de estas plazas, podía suponer un grave desprestigio para su persona, así como un duro revés en sus aspiraciones de obtener un cargo de mayor prestigio dentro del cursus honorum de la Monarquía. Por lo que, aunque pueda parecer que las conclusiones de dicha junta carecían de trascendencia, pues fuera cual fuera el resultado de la misma, Hurtado de Corcuera no estaba dispuesto a desamparar totalmente ninguna área de influencia, estas sí sirvieron para reforzar su posición. De modo que, los dictámenes expresados en esta reunión, refrendaron frente al Consejo de Indias la decisión del gobernador de reducir los recursos remitidos hasta Taiwán, disminuir la presión militar en la zona y concentrar los esfuerzos en el presidio de San Salvador, desmantelando el emplazamiento de Santo Domingo y el resto de fortalezas circundantes. Dejando claro, que el mantenimiento de la presencia hispánica en Isla Hermosa iba a tener un papel secundario durante su mandato ${ }^{7}$, pues consideraba más prioritaria la actuación en otros frentes.

Pero, al margen de las decisiones tomadas por el presidente de la Audiencia, las discusiones llevadas a cabo en el ámbito de esta junta de guerra, nos llevan a hacernos varias preguntas: ¿Por qué después de tan solo once años de presencia en Isla Hermosa, los principales miembros de la Gobernación apostaron por abandonar este territorio?, ¿por qué se tomó en primer lugar, si se demostró tan rápidamente que hacerlo pudo ser un error?, y si se probó su escasa validez para los intereses de la Corona ¿por qué se conservó hasta la conquista neerlandesa de i642?. Para intentar resolver estas cuestiones, hay que tener en cuenta que la presencia hispánica en Taiwán respondió a varios factores, y que estos se vieron ampliamente influenciados por diversas dinámicas que afectaron tanto a la Gobernación de Filipinas como a los países del sureste asiático durante la primera mitad del siglo XVII. De modo que tanto el presidio de San Salvador, como el resto de enclaves de la Monarquía

con que se tomó aquel puesto, que fue el estorvar al enemigo mindanao no viniese a infestar estas yslas. Y antes viene con más fuerça de armada que ya a hecho mayores daños». AGI, Filipinas 21, R.11, N.55.

Parecer de Alonso García Romero en la junta de guerra sobre el estado de los presidios, Manila, 22/01/1637.

6. «Los grandes gastos que su magestad a hecho en conservarle y que esto supuesto, y la falta de dinero que ay en estas yslas y la falta de gente española que las defienda, parece ynsta mucho a que se haga el dicho retiro, pues para reducir ai más, que es el principal fin, dentro de casa ay muchas podiendose haçer la conquista con menos gasto y rriego. Y lo principal a que se debe atender es el fortificar a Manila y las plaças a ellas sujetas, estando aperçevidas para los enemigos que las infestan. Y ssi se continuase el socorrer a la dicha fuerça de Ysla Hermosa, es cierto se a de debilitar esta y perder los puestos neçessarios por los que no son de provecho». AGI, Filipinas, 21, R.11, N.55. Parecer de Antonio Álvarez de Castro en la junta de guerra sobre la viabilidad de los presidios, Manila, 22/01/1637.

7. «Como quiera que entre los soldados onrrados es de tan gran mengüe el desamparar las fuerzas, no e querido usar de los pareçeres de la dicha junta. (...) Por lo qual embió ahora al sargento mayor Pedro Palomino, soldado que a muchos años que sirve a Vuestra Magestad en estas yslas en las armadas. Y en esta ocasión, pasada de la toma del Mindanao, me a ayudado muy bien, ba con 100 moqueteros pampangos y que quede allá con 50 o 60 españoles, los mejores». AGI, Filipinas 21, R.11, N.55. Carta de Sebastián Hurtado de Corcuera, Manila, 20/08/1637. 
en Formosa, no fueron elementos aislados y ajenos a su entorno, sino que compartieron tendencias, necesidades y circunstancias tanto con el resto de territorios asiáticos como con aquellos enclaves bajo el amparo de los Austrias. Viéndose a su vez afectados, por las crecientes alteraciones de un entorno que vivió una época de profundos cambios. Por lo que, en los siguientes puntos, vamos a contemplar desde distintas ópticas, cuáles fueron las razones que llevaron a los hispánicos a tomar Isla Hermosa, cómo esta nueva pieza encajó dentro del entramado de la Monarquía y como los cambios acontecidos en el continente alteraron su papel inicial.

\section{TAIWÁN EN EL CONTEXTO DEFENSIVO DE LA GOBERNACIÓN DE FILIPINAS}

Con más de 7.00o islas, un interminable e irregular litoral, elevados sistemas montañosos y profundos e impenetrables bosques interiores, la defensa del archipiélago filipino supuso un verdadero desafío para la Monarquía Hispánica desde el momento de su conquista. Por lo que ante la imposibilidad de mantener tropas y fortificaciones en todo el territorio controlado, se decidió tejer un intrincado sistema que permitiera, por medio de la defensa de los principales pasos y vías marítimas, mantener libre de enemigos las aguas interiores del archipiélago, creando un hinterland acuático filipino orquestado desde Manila. Para ello, además de concentrar un gran número de tropas en la bahía de Cavite, se edificaron una serie de fortalezas en distintos puntos estratégicos. En la frontera norte, en las cercanías de Lalo, se levantó el presidio de Nueva Segovia, desde donde se podía controlar tanto la inestable provincia de Cagayán, como las posibles amenazas llegadas desde el mar de China. En el que la piratería sino-japonesa de los wokou y las malas relaciones mantenidas con Kyoto, pusieron en alerta en más de una ocasión a las altas esferas de la Gobernación ${ }^{8}$. En las Bisayas, se alzaron presidios en Iloilo y Cebú, que junto al de Calamianes en Palawán, tenían como misión, interceptar a los navíos procedentes de Mindanao, Joló y Brunéi que osaran adentrarse en las aguas filipinas. Estos sultanatos meridionales, contaron durante gran parte del siglo XVI con una intensa actividad pirática, que afectó principalmente a las zonas costeras interiores del archipiélago y a los pequeños poblados dispersos a lo largo y ancho de las Bisayas. Mientras que más al sur, ya en la propia isla de Mindanao, se erigía Caraga, un presidio a cargo de un alcalde mayor, con un importante hinterland propio, que sirvió como base para la realización de razzias en la isla. Esta red defensiva se complementaba con la presencia de diversas armadas de navíos, como la de Otón, que patrullaban los principales pasos costeros y realizaban incursiones punitivas en el sur. De manera que, el sistema defensivo se enfocó principalmente en minimizar la presencia de navíos enemigos en las aguas interiores filipinas, deteniendo su avance en sus inmediaciones o previniendo posibles ataques mediante el asalto a sus poblados costeros o a sus navíos. Hay que remarcar en este punto, que el

8. Herrera Reviriego, 2014. 
entramado filipino no se trataba de un elemento aislado o disociado del resto de territorios hispánicos y de su sistema defensivo ${ }^{9}$, pues mantenía cierta vinculación con el Pacífico americano ${ }^{\mathrm{IO}}$ y con el Estado da India, intercambiando información de posibles enemigos e intentando anticiparse a sus actuaciones ${ }^{\mathrm{II}}$.

Para este sistema defensivo, la presencia de la isla de Taiwán, suponía un elemento disruptivo que generaba una fuerte inquietud gracias a su capacidad para romper el statu quo de la región. Pues su considerable tamaño, el número de provisiones y géneros presentes en ella y su cercanía tanto al norte de Luzón como a Macao, hacían de esta isla una auténtica amenaza para la frontera norte filipina si en algún momento caía en manos de alguna potencia rival. Así como, una importante fuente de inestabilidad para el comercio chino o luso con Manila, ya que su posición era perfecta para el hostigamiento y presa de los navíos mercantes que se desplazaban por las aguas del mar de la China Meridional ${ }^{\mathrm{I} 2}$. Por lo que a pesar de que no se emprendió su toma hasta I626, la Gobernación de Filipinas, ya había considerado una posible conquista de Isla Hermosa desde finales del siglo XVI. La cual fue planteada en plena fase expansiva de la Monarquía en $\mathrm{Asia}^{\mathrm{r} 3}$, tras diversos desencuentros diplomáticos con Japón ${ }^{14} \mathrm{y}$ la aparición de rumores que apuntaban a la posibilidad de que el shogunato estuviera interesado en tomar la isla ${ }^{15}$. Por lo que algunos hispánicos, como el propio Luis Pérez das Mariñas, sugirieron que anticiparse a los japoneses en la toma de Formosa, no solo valdría para evitar el acercamiento de la frontera con Japón a solo unas pocas horas de viaje, sino que también permitiría obtener más información sobre la situación de Kioto y Beijing, sin el peligro que suponía estar presentes en sus propios territorios ${ }^{16}$, como le ocurría a Macao con China. Del mismo modo, la presencia de una fortaleza castellana en Taiwán, y su cercanía a las costas de

9. «Digo señor, que las filipinas son de la ymportançia que muchas vezes e rreferido (...). Que los enemigos de Olanda hazen por apoderarse de aquellas riquezas (...). Y que si se acaban de apoderar de todo aquello, como es çierto que lo harán aora con las armadas que llevan, no yendo en su seguimiento a estorvarle an de ser los más ricos y poderosos del mundo. Y no an de contentarse con ynquietar y destruir al Pirú y Nueva España, que tan façilmente lo harán siendo señores del mar del sur, sino que an de atreverse a más». AGI, Filipinas 30, N.32, Carta de Martín Castaño, Manila, 4/11/1624.

10. Crailsheim, 2014 .

11. «Tuve aviso que en el Pirú se esperaban quarenta vajeles de enemigos olandeses y ingleses, y que se quedavan fortificando los puestos más ynportantes de aquella costa por vía de Malaca. Tuve también el mismo aviso con una galeota que llegó de Nagapatán, por la qual se supo el socorro extraordinario que vuestra magestad avía mandado hazer aquella plaça con unas urcas o paraches que vinieron despachados de Lisboa. Pareciome que estos dos avisos me podían dar cuydado, porue ajustarán el uno con el otro y que si la armada del enemigo que se aguardava en el Pirú desgarrava de allí por no dexarla hazer pie (como tuve por cierto) podría ser venir a parar a estas yslas con fuerça bastante para poner en cuidado esta ciudad y intentar alguna facción contra el puerto de Cavite». , Filipinas, 21, R.3, N.14. Carta de Juan Niño de Távora, Manila, 1/08/1629.

12. «Que estando allí los japones, por no estar más que çinquenta leguas de Cagayán, vendrían a guardar los navíos chinos si algunos viniesen a esta ciudad a rroballos a la vuelta». AGI, Filipinas, 18B, R.7, N.66, Parecer de Luis Pérez das Mariñas en junta de guerra, Manila, 22/06/1629.

13. OLLÉ, 2002.

14. Borao Mateo, 2002. Cabezas, 1995.

15. «El Ilamado fray Martín de la Açençión, mártir que fue al dicho reino aviendo hecho una rrelación y apuntamientos de cossas convenientes y tocantas al servicio de dios y su magestad,(...) me avisa de lo mucho que para el bien de esta tierra conviene hazer jornada a las Ysla Hermossa y dize las rrazones siguientes». AGI, Filipinas, 18B, R.7, N.66. Parecer de Luis Pérez das Mariñas en junta de guerra, Manila, 22/06/1629.

16. Sobre los intentos castellanos de establecer un enclave denominado «el Pinar» en las cercanías de Macao ver: De SOUSA PINTO, 2014. 
estos países, podría amedrentar a chinos y nipones en caso de que estos plantearan emprender un ataque a la costa de Luzón ${ }^{17}$. Al mismo tiempo, que permitiría la consolidación y aumento del comercio con las provincias chinas de Guangdong y Fujian, así como la difusión de misioneros entre estas regiones ${ }^{18}$. Suponiendo también su conquista, un alivio para la provincia de Cagayán y la frontera norte filipina. La cual, según das Mariñas, se tendría que reforzar militarmente en caso de que Isla Hermosa cayera en manos de los japoneses ${ }^{19}$. Además, la presencia de una potencia como Japón tan cerca de la frontera septentrional, podía avivar el fuego de las revueltas internas que se daban en la región, dificultando el ya de por si precario control de muchas de sus áreas por parte de la Monarquía. Mientras que el establecimiento de un emplazamiento hispánico en Formosa, podría reforzar la solidez del sistema defensivo del hinterland acuático filipino, extendiendo su limes en el norte. Puesto que podría actuar como primer escoyo o puesto de información en la vanguardia, ante una hipotética conquista de Luzón por parte de alguna de las potencias asiáticas ${ }^{20}$.

Finalmente, y a pesar de los numerosos informes que las autoridades filipinas manejaban al respecto, la conquista de Isla Hermosa por parte del shogunato no llegó a realizarse. Siendo más una inquietud hispánica fruto de unos rumores posiblemente intencionados, que una posibilidad real. Puesto que resulta difícil creer que el Japón de finales del siglo XVI, tras los sucesos de Corea, envuelto en una gran inestabilidad interna y en el preludio de la batalla de Sekigahara, pudiera aventurarse en una empresa como esta. Por su parte, las autoridades y altos cargos de la Gobernación, aunque estuvieron mayoritariamente de acuerdo con la toma de Taiwán, como quedó reflejado en la junta de guerra celebrada en Manila el 22 de junio de 1597 , decidieron aplazarla hasta conseguir los recursos suficientes para ello $^{21}$. Puesto que, por estas fechas, la Monarquía tenía abiertos diversos frentes

17. «Por estar tan zerca i a mano para qualesquier cosas tocantes a China como a Japón, porque no dexaría de convenir el estar allí españoles, así para tener más notiçia de aquel rreino y que esta tierra estubiese con menos rrezelos del, porque estando allí se podrían saver y entender mejor qualquier novedad o yntentos que ouviese, o para ympedirlos quando conviniese. De más de que en alguna manera le podría ser ocaçión de rreçelo e ympedimento para no atreberse a benir a estas yslas y pasar y daño nuestro biendo i dexando tan çerca de su rreino y tierra de españoles, que lo puedan hazer si ellos lo hiçiesen acá». AGI, Filipinas, 18B, R.6, N.52. Carta de Luis Pérez das Mariñas, Manila, 8/07/1596.

18. «Que si los españoles tienen aquel puesto, los chinos se holgarán mucho por tener con ellos su contratación, y tendrán más seguridad y creçerá la dicha contratación. Y será puesto y escala para tenerla mejor más çerca la contratación que agora la ay, y juntamente muy conviniente para las pretensiones del servicio de dios y de su magestad así para las cossas de China como de Japón». AGI, Filipinas, 18B, R.7, N.66. Parecer de Luis Pérez das Mariñas en junta de guerra, Manila, 22/06/1629.

19. «También ymportará para que el Japón no ocupasse i tomase primero esta ysla en daño nuestro, iendo poco a poco ganando tierra i acercándose a estas, como será no con pequeños inconvenientes, yquietudes de ella, el día que la tenga y ocupe por suia particularmente para la provincia de Cagaían, que está mui çerca y vezina de allí. La qual tendrá menester de neçessidad y para su seguridad, el día que esto aía, más defensa, fortificaçión i guarda de la que agora tiene». AGI, Filipinas, 18B, R.6, N.52. Carta de Luis Pérez das Mariñas, Manila, 8/07/1596.

20. «Que el enemigo que ay qué temer es Japón, estando allí los españoles le eynpedirán su passo u están en más defensa de esta ciudad y pueden dar presto avisso para qualesquiera prevención, por no aver desde esa ysla a aquella más de çinquenta leguas». AGI, Filipinas, 18B, R.7, N.66. Parecer de Luis Pérez das Mariñas en junta de guerra, Manila, 22/06/1629.

21. "Y aunque yo con resolución mandé lo que se avía de hazer, yré con la sonda en la mano hasta que me llegue socorro de jente y dineros de México, que sin esto no puede hazer la guerra». AGI, Filipinas, 18B, R.7, N.66, Carta de Francisco Tello, Manila, 22/06/1597. 
en Asia, como el moluqueño o el que les enfrentaba a los sultanatos meridionales filipinos, así como diversas revueltas interiores, que requerían del desplazamiento de un gran número de soldados, armas y caudales hasta puntos bastante alejados de la capital $^{22}$. Mientras que en Manila, las tropas disponibles eran escasas y las murallas de Intramuros requerían de una urgente reforma, tras haber sido severamente dañadas por el paso del tiempo y la cambiante climatología filipina. De todos modos, y a pesar de los grandes gastos militares y la actividad de otros frentes, el nuevo gobernador, Francisco Tello de Guzmán, decidió reforzar la posición de la Monarquía en el limes norte del archipiélago tras el abandono de la iniciativa taiwanesa. Para lo que remitiría tropas y caudales hasta Nueva Segovia, con el fin de apuntalar la presencia hispánica en Cagayán y proteger al archipiélago si finalmente la amenaza japonesa se cernía sobre Isla Hermosa ${ }^{23}$.

Con el inicio del siglo XVII, el progresivo cierre de fronteras y la definitiva unificación de Japón por Tokugawa leyashu, la tensión militar ${ }^{24}$ entre el shogunato y la Gobernación de Filipinas fue, poco a poco, cayendo en el olvido. De modo que, tanto Taiwán como la frontera norte de Luzón, fueron perdiendo paulatinamente su valor estratégico. Mientras que la fortaleza de Nueva Segovia, fue relegada a tareas de lucha contra la piratería de los wokou y de control de una provincia de Cagayán, que por estos años contaba con una conflictividad decreciente ${ }^{25}$. Por lo que al desaparecer la amenaza de que una potencia regional enemiga pudiera conquistar Isla Hermosa y la utilizara como punto estratégico desde el que bloquear comercialmente o atacar militarmente a Luzón o Macao, se perdió gran parte del interés por su anexión ${ }^{26}$. De modo que, las menciones sobre Taiwán encontradas en la documentación hispánica de las dos primeras décadas del siglo, son relativamente escasas, sobre todo si se comparan con las del resto de centuria. Es más, incluso el intento fallido del magistrado Murayama Tōan de establecer una base japonesa en esta isla en ${ }_{161} \mathrm{I}^{27}$ con la que comerciar con China, pasó inadvertido para las autoridades manileñas. Lo cual, no es de extrañar, puesto que durante estos años,

22. «Que le parsce no ay fuerças para hazer la jornada de Ysla Hermosa, y que aviendola se podrá hazer, y que tanbien advierte suya consideración a que se dize que el rrey de Tidore a muerto a los portugueses. $Y$ tomado la fuerça y aviendo de tener esta atención y gente para yr se haga la dicha jornada». AGI, Filipinas, 18B, R.7, N.66. Parecer del capitán Diego de Castillo en junta de guerra, Manila, 22/06/1597.

23. «Nuevos avisos an llegado del Japón, con dezir que ay yntento de ben[ir] a ocupar la Ysla Hermossa, que está zerca de estas yslas y es el paso desde China aquí. Boy mirando lo que convendrá en esto, porque aunque de parezer de tomarla primero, me lo contradije el consejo de guerra diciendo tenemos poca gente para ello. (...) A Cagayán e embiado dineros y persona para que se fortalezca el fuerte que allí vuestra magestad tiene, y si de la Nueva Spaña se enbía la gente y socorro que e pedido, no temeré toda la potencia de Japón, porque aunque aquí ay poca gente, es mui buena y bien exercitada». AGI, Filipinas, 18B, R.7, N.65. Carta de Francisco de Tello de Guzmán, Manila, 19/06/1597.

24. Hay que mencionar en este punto que, en cambio, durante estos años se produjo una elevada tensión religiosa entre la Monarquía Hispánica y Japón, propiciada, en parte, por la llegada de numerosos misioneros católicos a sus costas y la creciente persecución hacia este culto por parte de las autoridades niponas. Sobre las relaciones diplomáticas entre Manila y Japón ver: IACCARINO, 2017.

25. «La provincia de Cagayán está más quierta de lo que solía, reformose allí una compañía porque la guerra a çesado, esperanzas se tiene de que[a]brazen cada día más indios de paz». Carta de Juan Niño de Távora, 8 de julio de 1632, AGl, Filipinas, 8, R.1, N.16.

26. TREMML-WERNER, 2015:239-240.

27. ChenG, WEI-CHUNG, 2013. 
la atención de la Gobernación se focalizó más en otros frentes como el moluqueño, en el que las disputas contra el sultanato de Ternate y sus aliados neerlandeses por el control del comercio de las especias, concentraban muchos de los recursos y energías de la Monarquía en Asia.

Pero los hispánicos no pudieron ignorar mucho más tiempo la presencia de Taiwán, puesto que tras el fracasado intento de conquista de $\mathrm{Macao}^{28} \mathrm{y}$ tras la toma de Isla Pescadores en I622 por las fuerzas de la $\mathrm{VOC}^{29}$, la atención de los neerlandeses viró hacia Formosa ${ }^{30}$. Para los intereses de la Monarquía en Asia, la presencia de las Provincias Unidas en un enclave tan cercano tanto a Manila como a $\mathrm{Macao}^{3 \mathrm{I}}$, constituía una amenaza incluso mayor que la que había supuesto Japón. Debido a que convertiría a la isla en un importante foco de inestabilidad, que podría no solo poner en peligro la integridad de sus fronteras y la seguridad del hinterland acuático filipino, sino también la viabilidad del comercio. Puesto que los neerlandeses contaban con un acceso preferente al comercio japonés a través de Nagasaki y mantenían vínculos con algunas de las principales comunidades mercantiles chinas ${ }^{32}$, que como en el caso de las dirigidas por Li Dan ${ }^{33}$ o Zheng Zhilong, solían combinar el tráfico comercial con la piratería ${ }^{34}$. Por lo que la VOC y sus aliados, podrían utilizar su base de Taiwán, como núcleo para reforzar los asaltos de las aguas interiores filipinas y de las embarcaciones mercantes que cubrieran la ruta con Manila ${ }^{35}$ ante el descenso del potencial naval de la Gobernación ${ }^{36}$. Al mismo tiempo, que podrían encaminar el comercio chino hacia sus propios intereses, gracias a la cercanía de Isla Hermosa a la costa de Fujian, su posición preferente en la obtención de la plata japonesa y a un posible bloqueo de las vías de obtención

28. Según fuentes castellanas presentes en Macao, el objetivo de la VOC con este ataque era, además de saquear la ciudad, cortar las relaciones comerciales de ella con Japón, lo que en opinión de los neerlandeses provocaría el descalabro mercantil de Manila y la India. «La horden que Cornelio traya era que tomase esta ciudad de Macán y hiziese en ella su asiento y continuase el comerçio y buena correspondencia con el Xapón. Con lo que le pareció quedava por acavada esa ciudad de Manila y el estado de Philipinas y toda la Yndia». Biblioteca Nacional de Portugal (en adelante BNP), COD.CXVI/2-11, N.38. Copia de la carta del visitador de la Compañía de Jesús sobre la victoria de Macao, 1622.

29. "The Hollanders have sent great store of monies and provition to their fortefication at Piscadores, thinking to get trade with the chinas by one meaners o other». CoKs, 1883, vol.2: 336. Carta de Richard Cocks, 14/11/1622.

30. Los neerlandeses ya habían barajado la posibilidad de hacerse con Taiwán como alternativa a Macao con anterioridad a 1622. «Tiénese por cierto que el enemigo se ba a fortificar a la Ysla Hermossa por barios yndiçios y por una carta de Manuel Sañudo, casado en esta çiudad y prisionero de los olandeses». BNP, COD.CXVI/2-11, N.38. Copia de la carta del visitador de la Compañía de Jesús sobre la victoria de Macao, 1622.

31. «En la ciudad de Macao temen mucho que el olandés funde en esta ysla, porque si una vez funda, Macao queda destruido y la India acabada y sin trato». Archivo de la Provincia del Santo Rosario (en adelante APSR), Sección 33, Formosa, T.1, D.2. Alegato de fray Bartolomé Martínez en favor de la toma de Taiwán, sin fecha.

32. ANDRADE, 2007.

33. Sobre el papel de Li Dan en el comercio asiático ver: ICCARINO, 2020. IWAO, 1958.

34. Sobre Zheng Zhilong, también conocido como Nicolás lquan o Nicholas lquan ver: BLUSSÉ, 1990, BUSQUETS Alemany, 2007,CARIOti, 2006 y Ollé, 2009.

35. Como así dejó constancia en 1629 Peter Nuyts, factor de Fort Zeelandia, diciendo: «Debemos hacer todo lo posible para destruir el comercio entre China y Manila, por que tan pronto como se consiga esto, creemos firmementeque nuestras excelencias verán a los españoles dejar las Malucas, e incluso Manila por su propia voluntad». SCHURZ, 1985.

36. «The other two to goe for the Manillas, to meete and other Hollandes fleete, because they had certen news that 6 of the King of Spanies gallions, which was true, soe that the Spaniards hadd no strength to com out against them. So they took 3 China junckes more». Coks, 1883, vol. 2: 303. Carta de Richard Cocks a la EIC, 10/03/1619. 
de metales americanos en Filipinas ${ }^{37}$. Ante esta tesitura, y como ya ocurrió ante la amenaza japonesa de finales de siglo, la Gobernación estudió la posibilidad de establecerse ella misma en la isla antes de que lo hicieran las Provincias Unidas, pero el coste de la empresa y su complejidad, volvieron a retrasarla, por lo que finalmente se decidió no anticiparse y esperar acontecimientos ${ }^{38}$.

Solo dos años más tarde, en I624, la VOC tomó la iniciativa y se estableció finalmente en Taiwán, fortificándose en la bahía de Tayouan, al sureste de la isla. Este enclave, a pesar de presentar algunas deficiencias defensivas, resultaba perfecto para controlar los estrechos del mar de China, por situarse tanto cerca de las provincias de Fujian y Guangdong como de Macao y Luzón. La amenaza de que Isla Hermosa pudiera volverse un foco de inestabilidad se había vuelto una realidad, y solo un año más tarde, en 1625 , se sucedieron las penetraciones de las flotas neerlandesas en aguas filipinas. Por lo que las autoridades manileñas, temerosas ante las posibles consecuencias militares y comerciales que pudiera tener la presencia de los neerlandeses en sus aguas, comenzaron a desarrollar un plan para la toma de un punto estratégico en Taiwán, que contrarrestara el ascendente y la influencia de la VOC en las aguas del Asia pacífica. Pero en contra de lo que se pudiera pensar, la Gobernación no buscó fortalecerse en las proximidades del enclave neerlandés, como si ocurría por ejemplo en Ternate, sino que prefirió hacerlo en el otro extremo de la isla. Así pues, el 5 de mayo de I626, una expedición comandada por Antonio Carreño de Valdés salió de Cagayán rumbo a Taiwán, tomando la bahía de Jilong (Keelung) y construyendo en ella una fortaleza que sería conocida bajo el nombre de San Salvador. Por lo que mientras que el sureste de Taiwán se enmarcó dentro de la influencia neerlandesa, el norte haría lo propio con la hispánica.

Visto en perspectiva, la elección de situar un presidio hispánico en la parte septentrional de Formosa resulta, cuanto menos, sorprendente, sobre todo si se tiene en cuenta los hipotéticos beneficios de una fundación meridional. Así pues, la cercanía entre el sur de Taiwán y el norte de Luzón, podría haber facilitado en gran medida la conexión entre ambas islas, ahorrando importantes recursos en el traslado de víveres y pertrechos, así como generando unas comunicaciones más fluidas y estables. Mientras que podría haber asentado más sólidamente a esta plaza en el sistema defensivo filipino, pudiendo compartir más fácilmente recursos navales con Nueva Segovia en la defensa de los estrechos del mar de China y en la desarticulación de los wokou hostiles ${ }^{39}$. Además, su lejanía del núcleo neerlandés,

37. «El intento del olandés dicen es fundar en la Ysla Hermosa en el altura de veinticuatro grados e ir con armada a China y atemorizarlos, y decir que si pasan a Manila les ha de quitar vida y haciendas, que vayan a la Ysla Hermosa, que allí se las comprarán. Él comprará mucho para la Sonda y las demás factorías suyas, y para llevar a b al trato, hará corte así a los mercaderes japonés para que vengan allí a las compras. Y viendo el rey de Japón de cuanta utilidad esto lo es para su reino, le concederá todo cuanto pudiere, y es cierto procurará con toda verás quitar la comunicación y el trato de Macao y Manila. (...) Y el verdadero amigo del china es la plata, trayendo el olandés y el japonés mucha plata a la dicha ysla, es cierto impedirá el trato de Manila». APSR, Sección 33, Formosa, T.1, D.2. Alegato de fray Bartolomé Martínez en favor de la toma de Taiwán, sin fecha.

38. «Y aunque a don Alonso Fajardo, mi anteçessor, le previnieron que el olandés trataba de fortifiarse en ella y quanto importaría a estas islas ganarle el puerto, no lo hiço (quiça por no poder más) y oy tiene una fuerça de quatro baluartes». AGI, Filipinas, 7, R.6, N.83. Carta de Fernando de Silva, Manila, 4/07/1625.

39. «Este puerto, una vez fundado, no podrá el enemigo coger la ropa que viene de China, porque luego que 
daba mucho más margen de maniobra a la VOC para asentarse en la región y desarrollar una política comercial y agrícola más activa. Al mismo tiempo que generaba importantes dificultades comunicativas, puesto que los navíos hispánicos debían pasar por las inmediaciones del puerto neerlandés para alcanzar el norte de Taiwán. De todos modos, hay que tener en cuenta que las autoridades de la Gobernación, desde los primeros compases de su presencia en la isla, fueron conscientes de que no disponían de recursos suficientes para expulsar a los neerlandeses de la misma ${ }^{40}$, por lo que podrían haber evitado tomar una localización más próxima, que irremediablemente significara un conflicto directo que no podían ganar.

Por otra parte, y a pesar de las evidentes desventajas, la elección del área septentrional de Formosa no estaba exenta de posibilidades, aunque estas estuvieran más vinculadas con los ámbitos comerciales y evangélicos que con los militares o comunicativos. Por lo que, aunque las capacidades defensivas y portuarias de San Salvador, fueran sensiblemente superiores a las de enclave elegido por la VOC y contara con importantes recursos agrícolas y ganaderos ${ }^{4 \mathrm{I}}$, el auténtico factor decisivo a la hora de su elección ${ }^{42}$, fue su cercanía a la costa de Fujian y al territorio japonés. Además, según los contemporáneos, las corrientes existentes en la isla, dificultaban la llegada de los navíos de la VOC hasta la plaza hispánica, a la vez que favorecían la llegada de navíos mercantes procedentes de Japón, Siam o del delta de Mekong ${ }^{43}$. Permitiendo también, la introducción de religiosos en los países de la zona, gracias a su cercanía a sus costas y la relación con sus comerciantes.

Una vez asentada, la nueva fortaleza de San Salvador se estableció dentro del sistema defensivo de la Gobernación, aunque esto no le privó de contar con una serie de particularidades y características propias. Las cuales, la diferenciaron de otros centros militares situados en el interior del archipiélago filipino y de su hinterland acuático, como Nueva Segovia, Otón o Cebú, que contaban con una mayor vinculación con Manila y sus dinámicas. En cambio, la nueva fortaleza taiwanesa, desarrolló diversos puntos en común con otros presidios situados en los limes

llegue a estas costas desde Cagayán, en breve tiempo, se pueden dar aviso a la dicha ysla, y cuando el enemigo esté entre la ysla y China, en una noche y un día se da aviso a China, y entonces o no saldrá ropa o saldrá en embarcaciones pequeñas y ligeras, las cuales no pueden coger». APSR, Sección 33, Formosa, T.1, D.2. Alegato de fray Bartolomé Martínez en favor de la toma de Taiwán, sin fecha.

40. «La fuerza que allí tienen a ya dos años y más que travajan en ella, en estado deve estar que para hechallos fuera abían menester estas yslas diferente poder del que tienen por agora». AGI, Filipinas, 20, R.20, N.136. Carta de Juan Niño de Távora, Manila, 20/07/1626.

41. «La tierra es abundante es de arroz y fertilíssima, porque en ella se cría todo lo que en España. [Roto] Ay tres minas de azufre que yo se, ay tres minas de oro de abundan los torboanes y parusarunes que están de este puerto diez y seis o veinte leguas (que por mar es viaje de un día) (...) tiene mina de Alcaparrossa, tiene crista y quien duda que debajo de él habrá diamantes. Tiene muchas perlas y ambar, tiene (...) pescado mucho y mui bueno, los pastos para ganados son inagotables por el rocío que cae todo el año, que nunca deha secar la yerba, mucha caça en los montes». APSR, Sección 33, Formosa, T.1, D.4. Relación del padre dominico Teodoro de Quirós, 1639.

42. «Y el fin con que se fortificaron fue ser passo de los navíos de Chincheo para Manila, y que el efecto que han conseguido es haver quitado casi del todo el comercio de la China con aquellas islas, pues aquel año no llegaron quarenta picos de seda y el enemigo se hallaba con más de novecientos, sin los texidos». AGI, Filipinas, 21, R.10, N.47. Carta de Fernando de Silva, Manila, 30/07/1626.

43. «Porque en tan corta distancia y grandes corrientes no puede estorvar el enemigo y desmantelar su plaça, por quedarle a tras mano y en la contra costa, y los japones, como no pueden passar sin seda, bernan por ella a nuestro puerto, trayéndonos la plata, con que somos dueños de todas sus contrataciones. Siam, Cochichina y Camboja, habiendo de pasar por aquel estrecho estimarán nuestra amistad y abrirase la puerta de la conversión». Ibidem. 
hispánicos, como con las plazas de lligan, Zamboanga (aunque esta fuera fundada nueve años más tarde que San Salvador, en i635) y, sobre todo, con la de Gamalama en Ternate. Con los cuales compartía una serie de características, apreciables fundamentalmente en su influencia sobre el territorio anexo, su carácter fronterizo, sus problemas de comunicación con otros puntos de la Gobernación y su particular organización interna.

Así pues, uno de los principales puntos en común entre estas tres plazas, fue que ninguna de ellas disponía de un gran territorio controlado ni hispanizado junto a la fortaleza. Y aunque es cierto que contaban con apoyos locales, como diversos pueblos indígenas en el caso de Isla Hermosa ${ }^{44}$, el sultanato de Tidore o los mardicas en territorio moluqueño o los conocidos como lutaos en Mindanao, estos mostraron en más de una ocasión un comportamiento voluble, no actuando conjuntamente o incluso tornando sus armas contra la Monarquía cuando esta no compartía sus intereses particulares. Esta situación, los diferenciaría claramente del resto de presidios del archipiélago filipino, ya que estos presentaban un mayor ascendente sobre el espacio anexo, un acceso más sencillo a productos agrícolas, favorecido por el pago de impuestos como los polos o las bandalas, y una mayor vinculación y subordinación de los cabezas de barangay y otros altos cargos de las zonas circundantes. Esta falta de un amplio territorio controlado junto al presidio generó, además, una serie de problemas para el autoabastecimiento de estos enclaves, que fueron especialmente intensos en Ternate y Taiwán, y que se verían agudizados por encontrarse muy distantes y relativamente aislados tanto de Manila como de otros puntos de importancia de la Gobernación ${ }^{45}$. Así pues, según testimonios de la época, durante algunos años, San Salvador solo obtuvo de manera autónoma agua y madera, teniendo que adquirir fuera de Taiwán el resto de elementos para el mantenimiento del presidio ${ }^{46}$. Por lo que, para la subsistencia de las tropas presentes en estos enclaves era necesaria la remisión de socorros anuales, compuestos principalmente por víveres, militares de refresco e importantes cantidades de plata ${ }^{47}$ destinada a pagar soldadas y obtener productos agrícolas o elementos bélicos de otros mercados regionales como China o Macasar ${ }^{4}$. Estos socorros suponían un gran desembolso para las arcas de la Gobernación, pues además del envío de estos suministros, requerían la fabricación, mantenimiento y remisión de los buques, que en ocasiones eran enviados formando pequeñas flotas para su defensa.

44. Sobre los pueblos indígenas taiwaneses ver: JACOBS, 2016.

45. «Por los malos tiempos o enemigos dexaje un año de entrar socorro en las islas, ni abría prestado ni propio de que vivir. Y quando en Manila lo pudiessemos passar quitando a los naturales y vezinos los frutos de la tierra para comer, en Terrenate, donde todo es de acarreo, por no llevar la tierra su sustento ninguno, y en isla Hermosa, donde los naturales no están de paz, ¿cómo lo avían de passar?». AGI, Filipinas, 30, N.12. Carta de Juan Niño de Távora, Manila, 4/08/1628.

46. «Y no en la Ysla Hermosa donde solo la leña y agua no se lleva para el sustento de los soldados». AGI, Filipinas 21, R.11, N.55. Carta de Sebastián Hurtado de Corcuera, Manila, 20/08/1637.

47. «La poca o ninguna importancia de aquel puerto de sustento y socorro 30.000 pesos cada año». AGl, Filipinas 21, R.10, N.47. Carta de Sebastián Hurtado de Corcuera, Manila, 11/07/1638.

48. «Fue servido que llegasse a aquella fuerça [de Ternate], una galeota de Macassar cargada de ellos, los quales se metieron en los almazenes por quenta de vuestra magestad, y assí quedó suplida la falta de ellas». AGI, Filipinas, 30, N.12. Carta de Juan Niño de Távora, Manila, 4/08/1628. 
Otra de las características comunes entre San Salvador, Ternate y Zamboanga, fue que todos estos presidios se encontraban situados en las inmediaciones de territorios en disputa y alejados de los limes de la Gobernación de Filipinas, por lo que presentaban una alta conflictividad y una intensa actividad bélica. De este modo, en Zamboanga, los hispánicos mantuvieron una intensa actividad punitiva sobre las comunidades musulmanas meridionales, con quienes compartían sus aguas y el extremo de la península que dio nombre al presidio. Mientras que en San Salvador se llevaron a cabo importantes disputas tanto con los indígenas de Taiwán como con los neerlandeses situados en el sur de la isla. Encontrándonos una situación muy similar en las Molucas, aunque salvando las distancias, ya que hay que tener en cuenta que el potencial bélico del sultanato de Ternate era muy superior al de las comunidades indígenas de Isla Hermosa. Mientras que las tropas neerlandesas desplegadas en las inmediaciones de Halhamera y su territorio circundante eran más numerosas que las que se podían encontrar en el mar de China.

Del mismo modo, la elevada distancia que separaba a estos presidios de los principales puntos de decisión de la Monarquía en Asia y los escasos contactos que se tenía con ellos, agudizaron los problemas comunicativos y administrativos que tenían estos enclaves. Los cuales, unidos a su localización en zonas fronterizas con una alta conflictividad, y en los que era necesaria una toma rápida de decisiones, hicieron que se pusieran a cargo de un «gobernador». El cual, a pesar de encontrarse supeditado al presidente de Audiencia manileña, concentraba un gran número de funciones, extendiéndose sus atribuciones en los campos de la diplomacia, la guerra o la administración de la propia fortaleza ${ }^{49}$. Por lo que más que de presidios, podemos llegar a hablar de «subgobernaciones», siendo un modelo que volvería a aparecer dentro del organigrama de la Monarquía a finales de siglo en las islas Marianas.

Los numerosos gastos que suponían estas «subgobernaciones», el escaso impacto que tenían sobre la defensa del hinterland filipino, así como los escasos réditos directos que obtenía Manila de su mantenimiento, provocaron una corriente de opinión cada vez más crítica entre sus contemporáneos acerca de la permanencia de la Gobernación en estas plazas. La cual, era difícilmente rebatida por sus detractores, quienes en muchas ocasiones, veían reducidos sus argumentos al desprestigio que supondría para las armas hispánicas la retirada de estos enclaves y al revés que implicaría para la expansión del catolicismo en Asia ${ }^{50}$. Es más, en I626, el gobernador Juan Niño de Távora, llegó a plantear la posibilidad de abandonar Ternate $^{5 \mathrm{r}}$, al mismo tiempo que aludía que de seguir el estado de guerra prolongada

49. «El sigundo socorro fue en un navío, una galera y un bergantín a cargo de el general don Juan de Alcoraso que fue a retirar al sargento mayor Antonio Careño de Valdés (...) Y assí se echó mano de sucesor más blando y de más costilla y autoridad, al qual se dio título de alcayde de aquella fuerça y governador de la gente de guerra al modo que lo tiene el de Terrenate». AGI, Filipinas 21, R.3, N.14. Carta de Juan Niño de Távora, Manila, 1/09/1629.

50. «La raçón más principal y que más debe mover a vuestra magestad, como príncipe tan cathólico, heredero del çelo christiano de los reyes sus antepasados, es que aquel puesto es llave maestra para abrir las puertas al evangelio en los reynos de China, pues de la tarde a la mañana pueden en enbarcaciones pequeñas entrarse los religiosos por aquellos ríos de China, que con este hipo salimos de España». AGI, Filipinas 20, R.20, N.136. Relación de Melchor de Manzano, provincial de Santo Domingo, Manila, 1627.

51. «Y si nada de esto se puede hazer, cierto que es gran lastima gastar todos los años tanto, sin provecho 
con los neerlandeses «no tendremos en esta de Isla Hermosa más ventajas que en las de Terrenate $\aleph^{52}$. Esta corriente crítica, fue agravada en el caso de Taiwán, por los numerosos problemas que encontró la Monarquía en su asentamiento en la isla. Puesto que el control del territorio septentrional no fue tan sencillo como se pudiera pensar, y desde un primer momento, se sucedieron las fricciones con las poblaciones indígenas circundantes al presidio. De modo que, los avances territoriales realizados, tuvieron que ser consolidados con el desarrollo de un sistema defensivo interno, encabezado por San Salvador y reforzado con la construcción de un nuevo presidio denominado bajo el nombre de «Santo Domingo» y una serie de pequeñas fortalezas subordinadas a la figura del gobernador de Isla Hermosa. Estos puntos, fueron víctimas de numerosos ataques por parte de las poblaciones locales y contaron con menores recursos y construcciones más precarias ${ }^{53}$. Por lo que, mientras que en I636 San Salvador contaba con I7 piezas de artillería, el presidio de Santo Domingo lo hacía únicamente con 8, las fuerzas de San Millán y San Antón con 4 y la de San Luis solamente con 3. Además, el servicio en estos enclaves debió resultar sumamente difícil y penoso, como se refleja en el hecho de que el «subgobernador» Alonso García Romero castigara a cuantos vivían amancebados en San Salvador con, en palabras de sus contemporáneos, el «destierro» al fuerte de Santo Domingo ${ }^{54}$. La evangelización, y con ella, la hispanización del territorio, tampoco tuvo los frutos esperados, y a pesar de los esfuerzos de los dominicos, un escaso números de indígenas abrazaron fervientemente la religión católica. Mientras que la utilización de Taiwán como plataforma para la entrada de misioneros en China y Japón tampoco alcanzó los resultados deseados, siendo más sencillo realizarlo desde los navíos mercantes que llegaban a Filipinas.

\section{TAIWÁN EN EL CONTEXTO COMERCIAL DE LA GOBERNACIÓN DE FILIPINAS}

La Gobernación de Filipinas vivió durante finales del siglo XVI y principios del siglo XVII una época de floreciente crecimiento comercial, fundamentado, en gran medida, por su papel como punto de encuentro entre la red mercantil asiática y la americana. La ciudad de Manila cumplió con un papel destacado en estos contactos, funcionando como epicentro del nexo entre estas dos redes y erigiéndose junto a Acapulco como dos de sus principales eslabones, gracias a

\footnotetext{
ninguno, y que casi sería mexor dexarlo del todo para volverlo a tomar en mejor ocasión». AGl, Filipinas, 20, R.20, N.136. Carta de Juan Niño de Távora, 20/07/1626.

52. Ibidem.

53. «Las pieças y forma de fuerça que tiene la de Tanchui, por nombre Santo Domingo, (...) y propoçión es de tres cavalleros de madera y una garita con su lienço corrido que queda en quadra. Mal traçada, por ser el sitio grande, y no benir los tres cavalleros». Archivo Histórico Nacional (en adelante AHN), Diversos-Colecciones 34, N.39. Informe de Alonso García Romero, 12/07/1636.

54. «Es público en esta ysla que de noche a desoras salía y salió de su casa muchas noches a prender algunos que se decía estar amancebados. Y a uno de ellos que es un alférez reformado tubo presso de veces y desterrado a Tanchuy». AGI, Filipinas 41, N.35. Testimonio del alférez Fabián Rubio en el juicio de residencia de Alonso García Romero, San Salvador, 12/07/1635.
} 
ser los puntos de conexión del conocido como «Galeón de Manila»\$5. Este viaje transpacífico, unía anualmente ambos continentes por medio de un único viaje, que aunque guardaba gran número de continuidades, también poseía una serie características diferenciadas según su punto de embarque. Así pues, si el galeón partía desde Manila, su carga solía componerse de gran cantidad de mercancías llegadas desde distintos rincones del Asia marítima, que podían comprender, desde exóticas sedas, tafetanes, damascos, especias y porcelanas, hasta tejidos sencillos de algodón y tallas religiosas. Mientras que si el galeón se embarcaba desde Acapulco, transportaba normalmente soldados de repuesto, bienes de tipología americana y europea, suministros militares y grandes cantidades de plata, tanto de comerciantes privados como de la propia Corona.

La llegada de este metal argénteo suponía un auténtico polo de atracción para los comerciantes del Asia marítima, por tratarse de un elemento realmente escaso en la zona, pues únicamente existían minas de importancia en Japón, y en menor medida, en Persia. Así como, por ser uno de los pocos productos que poseían una fuerte demanda por parte del mercado chino, de cuantos se podían encontrar allende de sus fronteras ${ }^{56}$. De este modo, Manila se convirtió en uno de los principales centros de intercambios del Asia marítima, recibiendo cada año la visita de un gran número de navíos de distintas partes del continente, siendo los más numerosos aquellos que procedían de las provincias chinas de Fujian y Guangdong, así como de la ciudad lusa de Macao.

El gran volumen de beneficios derivados del tráfico de mercancías, así como la elevada demanda de productos asiáticos en América, acabó desarrollando en la Gobernación una economía intensamente vinculada con el comercio y especialmente centrada en intercambio de mercancías procedentes de Japón y China con Nueva España ${ }^{57}$. De modo que las propias instituciones manileñas, focalizaron sus esfuerzos en asegurar, expandir y dinamizar este trato, llegando incluso a desatender, durante muchas décadas, otras fuentes importantes de ingresos, como la promoción de una agricultura comercial para la exportación, el desarrollo del mundo rural filipino o la intensificación y articulación del mercado interior en el archipiélago.

No es por tanto de extrañar, que la Audiencia y los vecinos de Manila, se sintieran profundamente turbados, ante la amenaza que suponía para sus formas de vida y para la propia economía de la urbe, el posible bloqueo desde Isla Hermosa del trato entre China y Luzón por parte de los japoneses ${ }^{58}$ o de los neerlandeses ${ }^{59}$.

55. Sobre el Galeón de Manila ver: Alfonso mola \& Martínez ShaW, 2003. Giráldez, 2015. YUSTE, 1984.

56. OLLÉ, 2005: 277-278. WANG, 2017.

57. FLYNN \& GIRÁlDEZ, 1996

58. «Dize que a de venir a ocupar aquel puerto (...) el primero que çesará [será] la contratación de China con esta ciudad, con lo qual es notorio no se puede sustentar ni mantenerse esta tierra. Por caussa que la dicha ysla está mui cerca de China y es necesario que todos los navíos de contratación que vienen a esta ciudad reconozcan aquellas tierras, a los que se les robará e ynpidirá el paso». AGI, Filipinas 18B, R.6, N.56. Carta de fray Juan Pobre, 1596.

59. «Los olandesses se infortifiado en Ysla Hermosa y ysla de pescadores, con que este año no an podido pasar a estas partes embarcaciones de China, y se ban saliendo con su yntento de quitar el trato y comercio de estas yslas, que es el camino más cierto para acabarlas si no se pone más remedio en ello que hasta aquí se a puesto». AGI, Filipinas 30, N.3. Carta de los oficiales reales de Manila, Manila, 10/08/1624. 
Miedo, que fue avivado, por el profundo descenso en la llegada de juncos chinos hasta la Gobernación durante en el inicio de la década de I620. El cual, estuvo originado por los reiterados asaltos neerlandeses, y en menor medida ingleses, a las naves asiáticas e hispánicas que navegaban en las inmediaciones de las aguas de Manila ${ }^{60}$. Así como a la inestabilidad política y social vivida en China en estos momentos y a la aparición de fuertes poderes personales en manos de distintos clanes familiares en sus costas.

Ante estos hechos, las autoridades y vecinos de Manila vieron en la toma de Isla Hermosa, una posible solución a este problema, puesto que permitiría desalojar a las naves neerlandesas del mar de la China Septentrional y asegurar el paso de los juncos chinos hasta la bahía de Cavite ${ }^{61}$. Además, la cercanía de Formosa a las costas de Fujian, podría facilitar la llegada de mercaderes chinos directamente a sus $\operatorname{costas}^{62}$, posibilitando el acceso hispánico a mercancías asiáticas por la vía taiwanesa, en el caso de que la entrada de estas a Luzón se encontrara impedida.

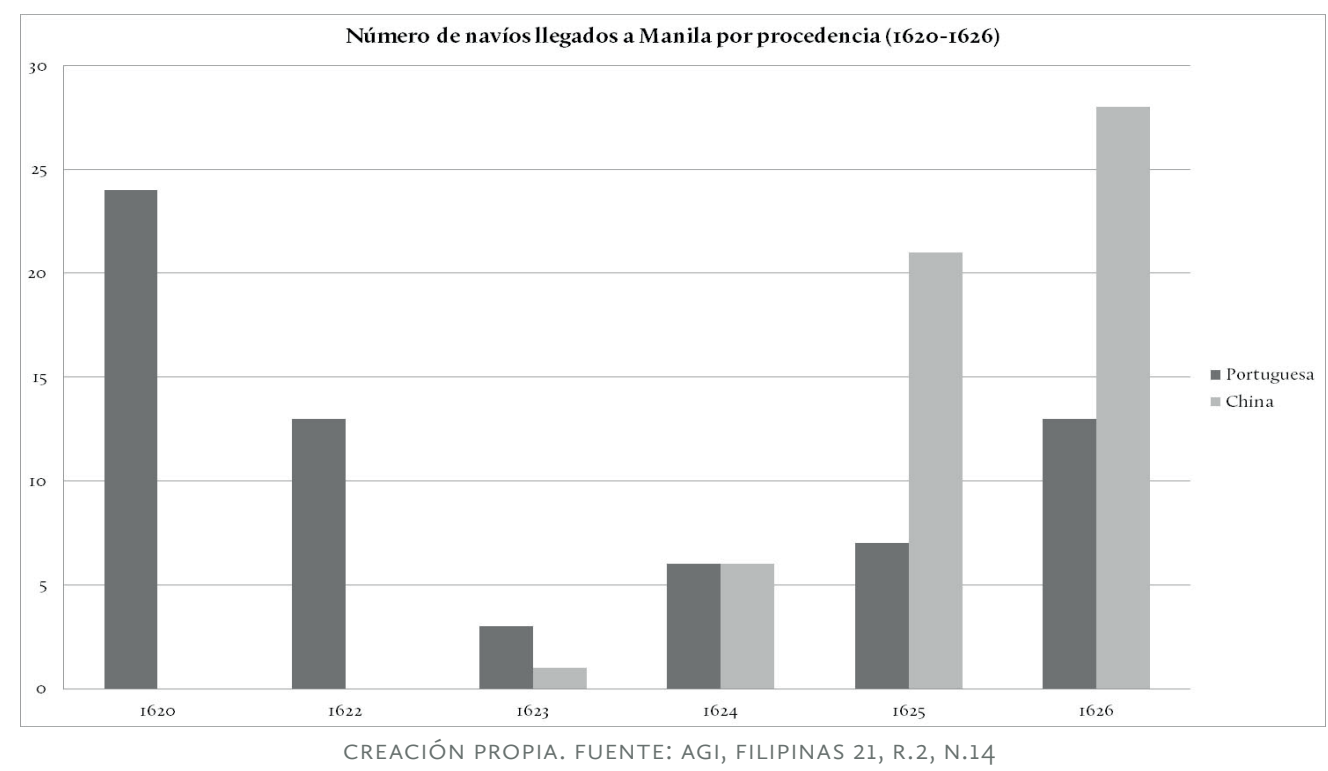

Por otra parte, la presencia de la VOC en Isla Hermosa, también puso en evidencia los intereses comunes entre Manila y $\mathrm{Macao}^{63}$ en el mar de China, así como la necesidad de la Gobernación filipina de defender las posiciones lusas frente al avance

6o. «Only they had taken 16 junks wich were bound for the Manillas; and were on the cost of Phillipinas, where they burned a Spanish ship, all the people being gon ashore». Coks, 1883, vol.2: 40. Extracto del diario de Richard Cocks, 6/06/1618.

61. «Y el fin con que se fortificaron fueser passo de los navíos de Chincheo para Manila, y que el efecto que han conseguido es haver quitado casi del todo el comercio de la China con aquellas islas, pues aquel año no llegaron quarenta picos de seda y el enemigo se hallaba con más de novecientos, sin los texidos». AGI, Filipinas 21, R.10, N.47. Carta del gobernador Fernando de Silva, Manila, 30/07/1626.

62. «Porque como está ysla está tan cerca de Chincheu, donde se hace el mayor trato que hay en China de mercaderes y por estar tan cerca de las partes más ricas de China, pueden pasar las mercaderías pequeñas y ligeras en muy breve tiempo». APSR, Sección 33, Formosa, T.1, D.2. Alegato de fray Bartolomé Martínez en favor de la toma de Taiwán, sin fecha.

63. De Sousa PINTO, 2014. Chang, 1933: 138-139. 
mercantil neerlandés. Puesto que la caída del comercio chino durante los primeros años de la década de I620 hasta Luzón, fue compensada ligeramente por la llegada de navíos portugueses procedentes de Estado da India y de Macao, permitiendo que los comerciantes manileños continuaran enviando productos asiáticos hasta Nueva España, a pesar de la ausencia de juncos en sus costas. De modo que el flujo comercial luso, a pesar de no poder equipararse al comercio chino ni en volumen potencial ni en márgenes de beneficios ${ }^{64}$, posibilitó la continuidad de las formas de vida de los vecinos de Manila, consolidando su economía y haciéndola más estable y menos dependiente de los vaivenes del trato con Fujian y Guangdong.

Pero, a pesar de los lazos cada vez más fuertes que unían a Manila y $\mathrm{Macao}^{65}$, de los intereses compartidos en la región y de la Unión de Coronas en la figura de Felipe Il, las autoridades de ambas urbes continuaron manteniendo cierta desconfianza mutua, mostrándose recelosas ante cualquier inferencia en sus jurisdicciones o amenazas en sus mercados. Por lo que los mandatarios manileños mantuvieron una actitud ambivalente respecto a $\mathrm{Macao}^{66}$, puesto que por un lado, necesitaban al comercio luso para consolidar su economía, mientras que por el otro, deseaban afianzar en la medida de lo posible el trato con los chinos, para no ser excesivamente dependientes de los portugueses, defender su singularidad en el continente y mantener su independencia económica respecto el Estado da India ${ }^{67}$. La presencia en Taiwán podría permitir alcanzar todos estos objetivos, pues su cercanía a la ciudad lusa haría posible apoyarla contra la inferencia de la $\mathrm{VOC}^{68}$, consolidando tanto su defensa como la seguridad de sus rutas comerciales con Manila, India y Japón ${ }^{69}$, sin que ello implicara una subordinación o dependencia respecto a las autoridades lusas o chinas, como si pudiera haber ocurrido de establecerse en un enclave continental ${ }^{70}$

64. «Esta ciudad tiene necesidad de harina para su sustento y bizcocho para las armadas, pertrechos de guerra, municiones y hierro. Si a Macao se envía por ello hase de comprar en la feria por medio de portugueses. Lo cual, me certificaron ser en gran detrimento de la hacienda real». APSR, Sección 33, Formosa, T.1, D.2. Alegato de fray Bartolomé Martínez en favor de la toma de Taiwán, sin fecha.

65. Sobre las relaciones entre Manila y Macao ver: García, 2008, LobATO, 2013, OlLÉ, 2014 y SouZA, 1986.

66. A pesar de los recelos mutuos, la Gobernación de Filipinas, llegó a aportar artillería y otros suministros para la defensa de Macao de los ataques neerlandeses. "De este buen ubçesso y victoria es cierto se deve la mayor parte a don Alonso Faxardo de Tença, governador y capitán general de las yslas Philipinas (...) Pues la artillería que tan a tiempo envió a aquesta çiudad fue la que hizon la barva y apartó tan apriessa al enemigo». BNP, COD.CXVI/2-11, N.38. Copia de la carta del visitador de la Compañía de Jesús sobre la victoria de Macao, 1622.

67. «Por las ordinarias competencias y emulaçiones de portugueses y castellanos en el comerçio de la China, deformidad bien grande siendo todos vassallos de vuestra magestad y tan apartados de sus ojos y entre tantos enemigos no vivamos unidos. Siendo assí que ni Manila puede passar sin Macán ni Macán sin Manila». AGI, Filipinas, 8 , R.1, N.10. Carta de Niño de Távora, Manila, 4/08/1630.

68. «En la ciudad de Macao temen mucho que el olandés funde en esta ysla, porque si una vez funda, Macao queda destruido y la India acabada y sin trato». APSR, Sección 33, Formosa, T.1, D.2. Alegato de fray Bartolomé Martínez en favor de la toma de Taiwán, sin fecha.

69. «Parece muy conveniente si ay posibilidad y disposición, desarraygar luego al olandés de Isla Hermosa, juntando a las fuerças de las Filipinas si fuere necesario las de Macán a quien tanto importa, así por la raçón del comercio, que es la principal, como porque esta isla Hermosa es el paso del viaje de Macán a Japón. Y tampoco porque no niego ser posible, haver tomado los olandeses puerto en Isla Hermosa para desde allí ganar a Macán de do[nde] están muy cerca, como lo intentaron el año de 622». AGI, Filipinas, 20, R.20, N.136. Propuesta de Juan de Carrizo, Manila, 20/12/1627.

70. «Estaremos después de fundados en las dichas costas de China esclavos de los chinos, como lo están los de Macao, comiendo por su mano, pudiéndonos quitar el sustento cuando quisieren y matar de hambre, comprándoles los alimentos al doble más caros de lo que valen en Cantón. (...)Pero en Ysla Hermosa estaremos de todo esto libres, 
como el Pinar ${ }^{71}$. Al mismo tiempo que afianzaría la posición hispánica respecto al comercio chino, estableciendo una vía secundaria por la cual fluir hasta Manila y una alternativa a la intermediación macaense.

Además, las autoridades de la Gobernación vieron en la presencia en Taiwán una posibilidad única para acercar posturas con Japón, puesto que, tras años de tensiones diplomáticas y religiosas, las relaciones con el shogunato se encontraban en un momento crítico, que culminó con la expulsión de los castellanos de las islas en $1624^{72}$. Con este mandato, Tokuwaga lemitsu dejaba a Manila en una seria desventaja comercial respecto al resto de sus competidores en la región, puesto que bloqueaba su acceso de las preciadas manufacturas niponas, a la vez que impedía la obtención de plata de las minas de Honshu. De todos modos, las autoridades manileñas no perdieron la esperanza y continuaron realizando contactos diplomáticos y conversaciones con mercaderes japoneses, con la intención de reanudar las conversaciones con el shogun y forzar una readmisión castellana ${ }^{73}$. Por lo que con los manileños fuera de escena, y ante la creciente tensión entre portugueses y japoneses, que derivó en la prohibición del trato con los lusos en I639, los neerlandeses se alzaron como los más beneficiados de las políticas restrictivas japonesas.

Los hispánicos se sintieron claramente amenazados por el creciente peso de las Provincias Unidas en el shogunato y su posición en Taiwán. Pues el acceso de la VOC a grandes cantidades de plata y su cercanía a las costas de Fujian y Guangdong, podrían desviar el comercio chino que acudía cada año de Manila hasta Isla Hermosa ${ }^{74}$, así como entorpecer los contactos entre Macao y Japón ${ }^{75}$. Es por ello, que la Gobernación también vislumbró la presencia hispánica en esta isla, como un método para obstaculizar el propio comercio neerlandés, puesto que la posición septentrional de la fortaleza de San Salvador era, teóricamente, más propicia para la arribada de buques nipones que la de los neerlandeses ${ }^{76}$, siendo una zona habitual de contactos

porque los chinos estarán a nosotros sujetos como en Manila y seremos sus señores». APSR, Sección 33, Formosa, T.1, D.2. Alegato de fray Bartolomé Martínez en favor de la toma de Taiwán, sin fecha.

71. Sobre los intentos hispánicos por establecerse en el Pinar ver: GIL, 2011: 98-100.

72. GORDON, 2003.

73. «El año pasado hubo en Japón una gran persecución y martirio de católicos, y aviendo llegado casi a este tiempo la enbajada que de estas yslas en nombre de vuestra magestad se embía al emperador no fue por entonces admitida ni despedida, quedavan los enbajadores con buenas esperanças, aguardando licencia para subir a la costa». AGI, Filipinas, 30, N.3. Carta de los oficiales reales de Manila, Manila, 10/07/1624.

74. «Y el verdadero amigo del china es la plata, trayendo el olandés y el japonés mucha plata a la dicha ysla, es cierto impedirá el trato de Manila». APSR, Sección 33, Formosa, T.1, D.2. Alegato de fray Bartolomé Martínez en favor de la toma de Taiwán, sin fecha.

75. «Esto lo dessean los portugueses de Macán porque el enemigo les haze daño en el passo para Xapón». AGI, Filipinas, 21, R.10, N.47. Carta de Sebastián Hurtado de Corcuera, Manila, 11/07/1636.

76. «Porque en tan corta distancia y grandes corrientes no puede estorvar el enemigo y desmantelar su plaça, por quedarle a tras mano y en la contra costa, y los japones, como no pueden passar sin seda, bernan por ella a nuestro puerto, trayéndonos la plata, con que somos dueños de todas sus contrataciones». AGI, Filipinas 21, R.10, N.47. Carta de Fernando de Silva, Manila, 30/07/1626. 
entre comerciantes chinos ${ }^{77}$ y japoneses ${ }^{78}$ durante la época de monzones. Así como una buena opción para desviar el trato de los mercaderes de Camboya, Tonquín y Siam de las factorías de la VOC hasta posiciones hispánicas.

\section{EL PAPEL DE TAIWÁN EN LA GOBERNACIÓN DE FILIPINAS TRAS 1626.}

En I626, la toma del presidio de Taiwán no parecía una resolución descabellada, pues a pesar de los grandes gastos que pudiera ocasionar, era capaz de mitigar la incertidumbre que ocasionaba la presencia neerlandesa en la región, reforzaba la frontera norte del archipiélago filipino y otorgaba nuevas respuestas a un posible bloqueo del comercio internacional con Manila. De todos modos, y tras solo unos pocos meses después de la fundación de San Salvador, comenzaron a aparecer opiniones que dejaban entrever sus reservas respecto a la presencia hispánica en Taiwán, como la del nuevo Gobernador, Juan Niño de Távora, quien argumentó que: «Las convenencias que para esto [la fundación de San Salvador] a avido muestran ser muchas, yo hasta agora no las e acavado de entender y pienso que solo el tiempo nos las declarará a todos ${ }^{79}$ ». El presidente de la Audiencia no iba desencaminado en su declaración, puesto que fueron justamente el tiempo y los cambios acontecidos en el continente los encargados de despejar las incertidumbres iníciales de la presencia hispánica en Isla Hermosa. Por lo que una vez las dudas se habían resuelto, la Monarquía se encontró con una costosa fortaleza que mantener, una población que subyugar y una ruta comercial que activar en un momento de urgencias económicas y militares.

Así pues, tras darse un importante descenso en el número de mercancías chinas transportadas hasta Manila a comienzos de la década de i620, como consecuencia de los ataques neerlandeses a los juncos que se encontraban en sus aguas y a los edictos Ming sobre el comercio internacional ${ }^{80}$, los siguientes años presentaron un importante repunte en su volumen. Destacando, sobre todo, el periodo comprendido entre i63I-I639, en el cual, las mercancías registradas en Cavite como procedentes de puertos chinos, no bajaron de los Io.0oo pesos en concepto de almojarifazgo, alcanzando incluso los 43.452 en I636. Cifras que contrastan con las de los años previos a la toma de Taiwán, pues en I623 las embarcaciones chinas solo pagaron I.759 pesos por esta tasa, mientras que tanto en 1620 como en $\mathrm{I} 622$, no se encuentran registros de ninguna embarcación ${ }^{81}$.

\footnotetext{
77. «The chinas of late tyme, within these 2 or 3 years, have begun a trade into certen islands called by them Tacca Sanga, and his name in ours seas cardes Isla Fermosa. (...) They sent 2 small junckes the last yeare, and bought silke for the one halfe they pay ether at Conchinchina or Bantam. The reason was the greate aboundance wich came together this year and the little money that was sent to buy, so that above one halfe was retorned into China for want of money, for they say the people are barbarous and have not the use of silver». Coks, 1883, vol.2: 298. Carta de Richard Cocks a la EIC, 15/02/1617.

78. Chen Chen, 2016. Cheng, Wei-chung, 2013. Tremml-Werner, 2015.

79. AGI, Filipinas 20, R.20, N.136. Carta de Juan Niño de Távora, Manila, 20/07/1626.

80. Cheng, Wei-Chung, 2013.

81. AGI, Filipinas 21, R.2, N.14. Informe de pagos en concepto de almojarifazgo en el puerto de Cavite.
} 


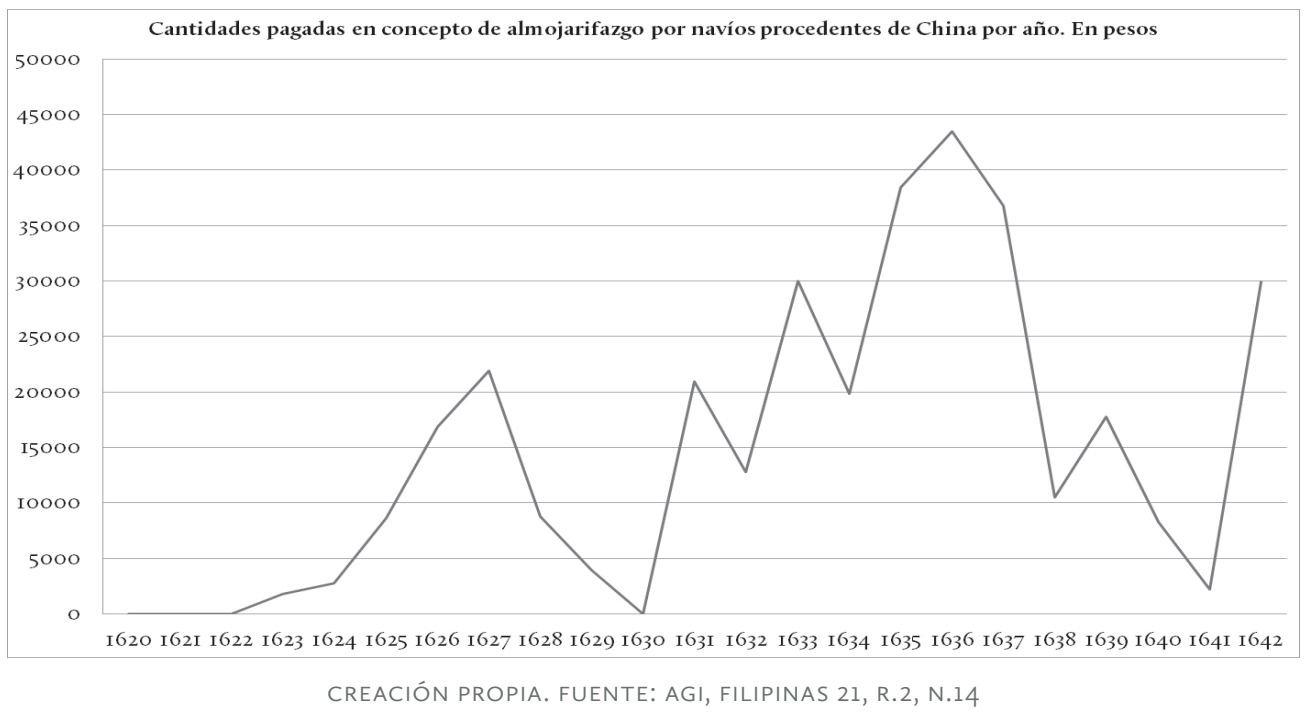

Aunque este incremento del comercio chino con Manila coincidió temporalmente con el inicio de la presencia hispánica en Taiwán, no estuvo únicamente condicionada por ella, teniendo mucha más influencia otros cambios sobrevenidos en los mares y costas de China. Así pues, en I627, aconteció en la provincia de Fujian una gran hambruna, y ante la escasez de alimentos, muchos de sus habitantes optaron por el comercio internacional y la inmigración para intentar escapar de la carestía ${ }^{82}$. De pronto, el Asia marítima se llenó de mercancías chinas, se intensificaron ampliamente los intercambios respecto a años anteriores y muchos fujianeses decidieron asentarse en otros territorios, entre los que destacarían especialmente Luzón o el sur de Taiwán. No es por tanto de extrañar, que fuera precisamente en este año, en el que se registró una mayor afluencia de mercancías chinas hasta Manila de toda la década de i620. Aunque los verdaderos beneficiados de esta crisis alimenticia fueron el talasócrata Zheng Zhilong y su clan, quienes intervinieron activamente en la difusión de esta población, desarrollando una actividad que combinaba el comercio con la piratería, y que les permitió extender su influencia tanto por los principales puertos chinos como por otras plazas como Manila, Macao o diversas ciudades costeras japonesas $^{8_{3}}$. El poder de este antiguo trabajador portuario llegó a ser tal, que en I628, el emperador Ming le concedió el reconocimiento oficial de su dominio sobre parte del litoral chino, a cambio de que pacificara sus estrechos ante la proliferación de los wokous. A su vez, este papel, facilitó a los Zheng la obtención de una posición central en el comercio de la región, deshaciéndose de numerosos piratas-mercaderes enemigos $^{84}$, legitimando sus actuaciones e integrando en sus redes a muchos de

82. «On account of the droughts, the harvest reaped in the spring of 1626 consisted of only half the normal amount of grain (in the fields of T'ung-an District). The following summer and autumn, the drought intensified in severity and the paddy fields were totally empty. Not until the spring of this year, 1627 , did a drop of rain fall. In the countryside, people have consumed all the roots and skins of any plants». Escrito de Ts'ao Lu-tai extraído de CHENG, WEI-CHUNG, 2013: 43.

83. CARIOTI, 1996

84. Las fuentes europeas y los oficiales chinos solían etiquetar a los presentes en las aguas del mar de China como «piratas» o «comerciantes» según su conveniencia. Es más, muchos de ellos combinaron ambas facetas con el 
sus antiguos rivales comerciales. El continuo ascenso de Zheng Zhilong acabó chocando con los intereses neerlandeses en la región, provocando la ruptura de las estrechas relaciones que la compañía comercial mantenía con este talasócrata hasta estos momentos e iniciando un intercambio de actuaciones punitivas que dificultarían las vías de entendimiento colaborativo entre ambas partes ${ }^{85}$. Esta inestabilidad se mantuvo hasta I633, fecha en que tuvo lugar un enfrentamiento bélico entre las naves de la VOC y los Zheng, que acabó decantándose claramente de parte del talasócrata, al que le sucedió un periodo de calma tensa, presidida por una intensa rivalidad comercial ${ }^{86}$. El crecimiento, consolidación y legalización del clan Zheng en los estrechos de Taiwán, así como su postura confrontada con los neerlandeses, acabaron desembocando en un importante crecimiento tanto en el número de navíos como de mercancías llegadas a Manila, teniendo su punto más álgido justamente en los años centrales de la década de i630. El cual, también pudo estar auspiciado por diversas políticas llevadas a cabo desde la Gobernación, que tenían como eje principal, el dotar de seguridad a los intercambios efectuados con los comerciantes chinos e impedir los agravios y abusos sobre la población sangley ${ }^{87}$.

Ante la incesante llegada de productos chinos directamente hasta la bahía de Cavite, el papel de Taiwán como vía secundaria para su obtención se acabó desdibujando. Así pues, con las bodegas de los galeones llenas de productos asiáticos y sin posibilidad de incrementar los envíos a Nueva España, ya que los contactos transpacíficos estaban limitados desde 1593 a un viaje anual ${ }^{88}$, la iniciativa privada de los comerciantes filipinos se alejó de Taiwán. Puesto que ¿para qué querrían correr los riesgos y pagar los sobrecostes de fletar una embarcación desde Manila hasta San Salvador y desde allí retornarla otra vez hasta Luzón ${ }^{89}$, si los propios mercaderes chinos ya les suministraban cuantos productos podían absorber?90 Aunque esta incesante llegada de manufacturas chinas hasta Manila no implicó una ausencia absoluta de intercambios entre Cavite y jilong, estos no tuvieron la afluencia ni los volúmenes de carga esperados en un primer momento, distanciándose ampliamente de los objetivos esperados. Así pues, los viajes comerciales entre Luzón y Taiwán, aunque existentes, fueron escasos, contando en su mayoría con la participación total o parcial de la Gobernación, puesto que en muchas ocasiones se aprovecharon

objetivo de maximizar beneficios. Por lo que algunos autores como Boyi Chen, los han definido como «mercaderes y también piratas». Chen, Boyi, 2018.

85. OLLÉ, 2005.

86. Esta inestabilidad se mantuvo durante años, desplazándose incluso al propio archipiélago insulíndico. BOON DAR, 2018.

87. «Y aviendo escussado los malos tratamientos que a los dichos chinas les haçían en esta ciudad (...) a continuado estos dos años en venir y traer tanta cantidad de mercadurías que los vecinos de treinta y más años de antigüedad no se acuerdan averlas visto más baratas». AGI, Filipinas 21, R.11, N.55. Carta de Sebastián Hurtado de Corcuera, Manila, 20/07/1637.

88. Yuste López, 2013.

89. Costes logísticos a los que se les tenía que unir el pago de los impuestos de almojarifazgo y fletes, que representaron respectivamente un $6 \%$ y un $8 \%$ hasta 1635 , fecha en que se subió la aduana hasta el $8 \%$, un $2 \%$ más que para los navíos llegados de China. Gil, 2011: 103-104.

90. «De que para el trato y comercio no es neçessario, respecto de que haciéndosele bueno a los mercaderes chinos trayen todos lo que an menester por su quenta y riesgo y los basallos de su magestad lo compran en sus propias casas». AGI, Filipinas 21, R.11, N.55. Carta de Sebastián Hurtado de Corcuera, Manila, 20/07/1637. 
los envíos de socorros hasta los presidios para trasladar mercancías hasta Manila. Por lo que no es de extrañar, que muchos de los altos cargos militares que sirvieron en San Salvador ${ }^{91}$, hicieran valer su acceso privilegiado a estos navíos de socorro para invertir en la compraventa de mercancías ${ }^{92}$. En cambio, los vecinos de la Gobernación, fueron perdiendo gradualmente su interés por esta ruta, debido principalmente a los escasos réditos y altos riesgos que implicaba este trato ${ }^{93}$. De todos modos, podemos encontrar diversos registros de embarcaciones capitaneadas por hispánicos sin mención alguna a la colaboración de la Corona, como en el caso de Carlos Baptista en I628, Antonio Matos en i630, Francisco de Araujo en I632, Juan de Gaceta y Uceta en I634 o Nicolás de Cortasa y Mateo López en i637. Así como de algunos sangleyes que cubrieron esta ruta, como, entre otros, «Hingcob» en I628, «Chinton» en I63I, «Chinuy» en I639 o «Suno» en I64I ${ }^{94}$. Aunque en estos casos hay que ser prudentes, pues las fuentes consultadas únicamente dan como referencia la última región en la que los navíos dieron fondo antes de llegar a Manila, no especificando ni el puerto ni el punto de inicio de la empresa, ni si los capitanes tenían relación alguna con Macao u otros entrêpots de la región. Por lo que muchos de los estos navíos, pudieron haber hecho una mera escala en Taiwán previa a su llegada a Luzón o haber atracado en cualquier otro de los puertos presentes en la isla controlados por los neerlandeses o bajo la influencia de los Zheng.

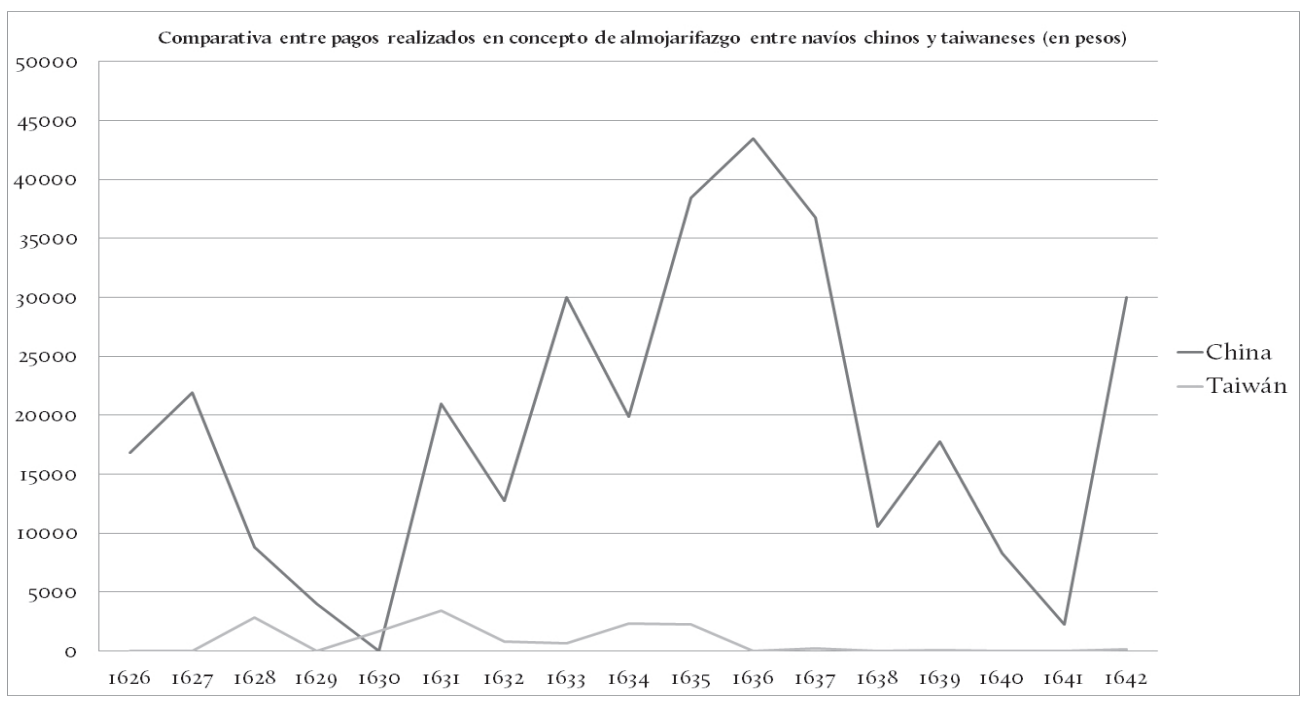

CREACIÓN PROPIA. FUENTE: AGI, FILIPINAS 21, R.2, N.14

91. «Y como después acá ben que no a habido en él más que un comprador, que es el general, y que los soldados por no socorrerlos de Manila, no tenían con que comprarles quatro tiborzillos de bino, ni la fruta, carne y pescado que trahían de China». APSR, Formosa, 33, T.1, D.8. Carta de Jacinto de Esquivel, 1632.

92. «El sarjento mayor Antonio García Romero, que venía de Governar aquellas fuerzas, fue de contrario pareçer porque a la verdad a él no le avía ydo mal para el aumento de su haçienda». AGl, Filipinas 21, R.11, N.55. Carta de Sebastián Hurtado de Corcuera, Manila, 20/07/1637.

93. «Que los tiempos an mostrado el poco o ningún fruto que su magestad a tenido ni los vecinos de esta ciudad con la toma de Ysla Hermossa, antes se sabe por cossa muy çierta los exeçibos gastos que se an echo de su Real Hacienda». AGI, Filipinas 21, R.11, N.55. Parecer del general Fernando de Ayala en Junta de Guerra, Manila, 22/01/1637.

94. IACCARINO, 2020: 228-229. 
En cualquier caso, los intercambios producidos entre Isla Hermosa y Cavite no mantuvieron unos flujos homogéneos, pudiéndose apreciar dos fases con intensidades y tendencias diferentes. Una inicial, que cubriría entre i628 y i635, en el que se intentaría abrir y consolidar los cauces comerciales, y una final, comprendida entre I636 y i642, en que la que se abandonaría el interés por este trato. Así pues, durante los primeros años de presencia hispánica se pueden vislumbrar ligeros y esperanzadores ascensos de la actividad comercial ${ }^{95}$, con destacados picos en I628 y i63i. Los cuales, no consiguieron asentar un flujo estable y continuado, debido en parte a la falta de liquidez presente en San Salvador, fruto del creciente desinterés privado en este trato ${ }^{96}$. Así pues, en 1632 , Juan Esquivel se quejaba de que en uno de los últimos socorros, los barcos de Manila, no había traído más que arroz para el consumo de las tropas. Por lo que ante la falta de plata, los comerciantes chinos que había portado sus mercancías hasta San Salvador, tuvieron que malvenderlas para no afrontar mayores pérdidas ${ }^{97}$. Mientras que Alonso García Romero, gobernador de San Salvador entre i634 y i636, afirmaba que durante su mandato habían llegado hasta Jilong mercancías chinas por el valor de 300.000 pesos, pero que en su gran mayoría no pudieron ser remitidas hasta Manila por no disponer de numerario suficiente para adquirirlas ${ }^{98}$.Esta situación, acabó desacreditando al puerto hispánico en Taiwán y generando un profundo desinterés entre los comerciantes chinos hacia esta ruta ${ }^{99}$, quienes decidieron invertir en empresas más seguras y rentables, abandonando casi completamente su vinculación con este emplazamiento hispánico. Esta tesitura generó un segundo periodo, comprendido entre i 636 y I642, que fue presidido por el limitado número de intercambios y la escasez de mercancías. En el cual, se alternaron años como I636 o I640, en los que no se registró ninguna embarcación, con otros como I639 o I64I, en que los pagos en concepto de almojarifazgo no alcanzaron ni los ioo pesos. Esta situación contrasta con la acontecida en estos momentos en la zona meridional de la isla ya que, a partir de las pugnas con los Zheng de I633, Fort Zeelandia conoció un significativo incremento en los intercambios comerciales con Fujian y Japón. El cual, fue posible gracias a un mayor entendimiento con las autoridades chinas y un acercamiento de posturas con Zheng Zhilong y su clan tras el conflicto previo ${ }^{\text {Ioo }}$. Del mismo modo, y como ya

95. «Es aver llegado de Ysla Hermosa el navío que fue por agosto a socorrer aquella plaça, trae buenas nuevas de lo mucho que cada día se adelantan nuestras cosas y de la esperanças con que se quedaba de abrirse el trato con la China, de donde avía venido cantidad de ropa y trigo de que vino cargado el navío a estas yslas». AGI, Filipinas 8 , R.1, N.12. Carta de Juan Niño de Távora, Manila, 27/11/1630.

96. «Y si hasta agora no han trahido sedas en abundancia a Ysla Hermosa ha sido por no aver olido allí dinero o muy poco. $Y$ ansí les ha sucedido ya ver bolverselas a su tierra por falta de compradores de que quedaron muy lastimados y perdidosen». APSR, Formosa, 33, T.1, D.8. Relación de fray Domingo de Aduarte, 24/11/1632.

97. BORAO MATEO, 2001.

98. «Y el trato dejé asentado en forma que se empleó los dos años más de 300.000 pesos de texidos y sedas de todos géneros, y por falta de dineros se volvían a China cantidad de sedas, rasos, terciospelos y damascos». AHN, Diversos-Colecciones, 34, N.39. Carta de Alonso García Romero, 12/07/1636.

99. «Nos desacreditan sumamente y publican no ay blanca por no haber tenido feria de sus cossas y que los hacen agrabio en las compras de la ropa, porque (...) les es fuerza el malbaratarla y darla en lo que él quiere o volverla a China y perderla por ser champanes sin chapa los que bienen». APSR, Formosa, 33, T.1, D.8. Carta de Jacinto de Esquivel, 1632.

100. BLUSSÉ, 1996. 
hemos podido comprobar, el espectacular descenso de los intercambios en Taiwán tampoco discurrió en paralelo en el puerto de Manila. El cual, a pesar de sufrir una reducción de los volúmenes de mercancías entre I638 y I64I, mantuvo unos niveles similares a otros periodos e incluso conoció importantes picos en i636 y I642.

Por otro lado, la presencia hispánica en Taiwán, tampoco acabó demostrando su aptitud para acercar posturas ni diplomáticas ni comerciales con un Japón que continuó con su proceso de aislamiento con nuevos edictos restrictivos. Así pues, en i633 Tokugawa lemitsu prohibió navegar a los japoneses fuera del archipiélago, limitando la entrada de navíos extranjeros en el país únicamente a aquellos que contarán con un permiso shogunal, al mismo tiempo que prohibía la vuelta al archipiélago a todo japonés que hubiera vivido más cinco años en el extranjero. Dos años más tarde, en I635, se dictaminó el retorno obligatorio a las islas de todos los japoneses que se encontraran fuera del archipiélago, decretando también la expulsión de todos los mestizos. Esta política aislacionista llegaría a su punto culminante en I639, año en que se prohibirá la entrada a los navíos portugueses en el país, cortando así casi un siglo de relaciones entre lusos y japoneses ${ }^{\text {Ior }}$. Ante la dureza de estos edictos, las autoridades manileñas intentaron acercar posturas con el shogunato, combinando propuestas de diálogo con amenazas hacia el comercio japonés ${ }^{102}$, que en algún caso llegaron a hacerse efectivas, como la toma de un junco en las costas de Siam en I628 que portaba más de 25.000 pesos en mercancías ${ }^{\mathrm{IO}}$. Aunque todo intento de reabrir el trato resultó en vano, y las autoridades japonesas no solo no retrocedieron, sino que endurecieron las restricciones. Aunque, de todos modos, los hispánicos siguieron manteniendo ciertas conexiones con los comerciantes procedentes del shogunato, tanto de manos de mercaderes de origen japonés como de intermediarios portugueses y chinos relacionados con los Zheng ${ }^{104}$. Estos contactos también se mantuvieron en Taiwán ${ }^{105}$, pues la bahía jilong ya era frecuentada por los juncos japoneses antes incluso de la fundación de San Salvador ${ }^{\mathrm{ro} 6}$. Por lo que ante los problemas para activar el comercio de la isla se planteó la posibilidad de utilizar el norte de Formosa como punto de encuentro entre los mercados chino y japonés, en el cual, los hispánicos actuarían como intermediarios. De forma que, la llegada de plata japonesa, compensaría la falta de inversiones privadas manileñas y la escasez de metales novohispanos, incentivando la llegada de manufacturas chinas, que a su vez consolidarían el flujo mercantil con

101. KONDO, 1999.

102. «Den a entender a los de su nación que si tuvieren buena correspondencia con Filipinas y me enviaren liçençia del emperador para que se vuelva a entablar el comercio como de antes, que nosotros corresponderemos con la amistad de vida (...) Que si continuaren en prohibir el dicho trato entenderemos quieren ser nuestros enemigos, y que assí serán tenidos y tratados por tales de las armadas de vuestra magestad». AGI, Filipinas 30, N. 12. Carta de Juan Niño de Távora, Manila, 4/08/1628.

103. RODAO, 1997.

104. AGI, Filipinas 21, R.2, N.14. Registro de navíos llegados a Manila entre 1626 y 1642.

105. «Nadie puede negar que aquí vienen los chinas y japones con mucha mercadurías como lo saben los que aquí han estado, e yo, que en un día entraron aquí veinte y tantos champanes cargados». APSR, Sección 33, Formosa, T.1, D.4. Relación de Teodoro de Quirós, 4/10/1639.

106. Chen Chen, 2016. Chen, Wei-Chung, 2013. 
Manila y la extracción y venta del mercurio local ${ }^{107}$.De todos modos, a pesar de las buenas perspectivas iníciales ${ }^{\mathrm{I0} 8}$, los intentos por utilizar Taiwán como llave para abrir el mercado japonés a los hispánicos no acabó funcionando, limitándose a unos escasos contactos comerciales que no destacaron respecto a los que la Gobernación ya disfrutaba en Luzón por parte de otros intermediarios.

\section{LA DECADENCIA HISPÁNICA EN TAIWÁN BAJO EL GOBIERNO DE SEBASTIÁN HURTADO DE CORCUERA}

El periodo de total decadencia comercial taiwanés comprendido entre i636 y I642, coincidió cronológicamente, con gran parte del mandato de Sebastián Hurtado de Corcuera al frente de la Gobernación filipina. Hecho que no resulta extraño, puesto que el nuevo presidente de la Audiencia, mantuvo una postura muy crítica con la presencia hispánica en Isla Hermosa y la utilidad de sus presidios durante gran parte de su mandato. Por lo que decidió reorganizar los recursos disponibles con los que contaba la Gobernación y encauzar sus esfuerzos hacia otras empresas, que en su opinión, eran más acordes con los intereses de la Monarquía en esos momentos. De modo que, su gobierno, como ya hiciera durante su estancia previa en Panamárog, se centró en la lucha contra la piratería, intentando conseguir por este método, la consolidación de las defensas de un limes acuático filipino que durante los últimos años se había mostrado completamente superado por el auge de razzias piráticas ${ }^{\mathrm{II}}$ y las penetraciones neerlandesas ${ }^{\text {III }}$. Así pues, Sebastián Hurtado de Corcuera, emprendió un proyecto para reforzar la frontera sur filipina, construyendo dos nuevos presidios en la isla de Mindanao, uno en la península de Zamboanga y otro en Iligán en i635 y i639 respectivamente. A la vez que acometía toda una serie de incursiones punitivas y campañas contra las sedes de los sultanatos meridionales, que le llevaron a atacar Buhayen y a Mindanao en I636 y a sitiar Joló en I638. Todo ello, mientras efectuaba la reforma de los sistemas defensivos manileños y apuntalaba las murallas de la ciudad tras los cuantiosos desperfectos ocasionados por las duras condiciones climáticas filipinas ${ }^{\mathrm{II} 2}$.

Esta actitud expansionista y beligerante demostrada por la Gobernación en el sur del archipiélago, contrasta con el continuo retroceso que tuvo lugar en el limes septentrional. El cual, estuvo fundamentado en gran medida, en la incapacidad de los presidios hispánicos en Taiwán para detener del avance territorial y

107. «Serbirá juntamente de acreditarnos este puerto por la mucha plata que suelen traer para comprar, con lo qual abrá abundancia de ropa y con ella abaratarán y abrá para comprar los unos y los otros. Pues el trato con los japones enriquecerá los españoles como ser solía, y no llorará tanto su codizia». APSR, Formosa, 33, T.1, D.8. Carta de Jacinto de Esquivel, 1632.

108. «Ysla Hermosa lo podrá tener seguro y barato, harto más que por Macán y más que los japones, como no pueden ir a China a buscar las sedas por serles muy prohibido, vendrán a Ysla Hermosa, como lo hizieron el año pasado dos champanes de ellos». APSR, Formosa, 33, T.1, D.8. Relación de fray Domingo de Aduarte, 24/11/1632.

109. González Alonso, 2012.

110. NEWSON, 2009.

111. Martín Onrubia, 2011. Temminck, 1855. Sloos, 1898

112. Diaz-Trechuelo Spínola, 1984. 
comercial de la VOC en la región. Esta situación no era nueva, puesto que tan solo dos años más tarde de la fundación de San Salvador, el gobernador Niño de Távora, escribió a Madrid una misiva en la que argumentaba que a pesar de lo precarias que eran todavía las defensas neerlandesas en la isla, la Gobernación no contaba con los recursos suficientes en Asia para detener el comercio de los neerlandeses en los estrechos y mucho menos para expulsarlos de la isla ${ }^{\mathrm{II}}$. Así pues, durante los siguientes años, los hispánicos, conscientes de las diferencias de recursos, llevaron a cabo mayores esfuerzos por afianzar su influencia en el norte de Taiwán y por controlar unas comunidades indígenas contrarias a pagar tributos, que en hostigar a las Provincias Unidas. De modo que, aunque durante el mandato del sargento mayor Alonso García Romero (I634-I636) llegaron a realizarse diversas incursiones en los territorios bajo influencia neerlandesa, los enclaves ganados no se conservaron, sino que simplemente se quemaron y abandonaron, debido a que no se contaba con los recursos ni el potencial militar para consolidar la posición hispánica en ellos ${ }^{\mathrm{II}}$. Después de la salida de García Romero de la capitanía general de San Salvador y con el nombramiento de Sebastián Hurtado de Corcuera como nuevo presidente de la Audiencia de Manila, el desvío de recursos hacia la frontera sur ${ }^{115}$ y la escasez de los socorros, agudizaron las diferencias estructurales y militares con el asentamiento neerlandés. A la vez que pusieron en entredicho la autoridad hispánica sobre el norte de la isla tras sufrir diversos reveses de importancia contra la población local. Así pues, en i639, mientras las tropas de la Gobernación retornaban victoriosas de las campañas meridionales, la Audiencia ordenó la retirada del presidio de Santo Domingo, después de que este hubiera sido parcialmente reconstruido tras el asalto llevado a cabo por los indígenas taiwaneses en I636, dejando a San Salvador como único bastión hispánico en la isla ${ }^{116}$. De modo que, la cada vez más acusada falta de tropas y la continua conflictividad con la población local, provocaron que poco a poco los hispánicos fueran retrotrayéndose dentro de los muros de sus fortalezas, abandonando la política expansiva en el norte de Taiwán y su proyección en la isla ${ }^{\mathrm{II}}$. Al mismo tiempo que, la Monarquía impulsaba la concentración de la guerra contra los neerlandeses en la defensa de sus principales plazas en la región: es decir Filipinas y Macao.

113. «La fuerza que allí tienen a ya dos años y más que travajan en ella, en estado deve estar que para hechallos fuera abían menester estas yslas diferente poder del que tienen por agora». AGI, Filipinas 20, R.2, N.136. Carta de Juan Niño de Távora, Manila, 26/07/1626.

114. «En la última entrada que hizo a la provincia de Cavalán, pasó un río en balsas de cañas con la infantería que pudo llevar, dexándo dos tropas de mosqueteros de manpuesto de la otra banda del río. Y aviéndole herido y muerto alguna gente, embistió de las trincheras del enemigo y se las ganó consiguiéndose la vittoria, ganándole un pueblo de los mayores y más fuertes de dicha provincia. Y por no poderle sustentar por ser mucha la fuerça del enemigo le pusso fuego». AGI, Filipinas 41, N.35. Parecer de Lorenzo de Olazo sobre el gobierno de Alonso García Romero, San Salvador, 9/07/1637.

115. Al final de su gobierno, Sebastián Hurtado de Corcuera fue acusado por varios tripulantes de los galeones de Manila de haber trasladado diversas piezas de artillería desde Filipinas hasta Acapulco, entre las que se contaba alguna con las que se defendió el cerro de Joló. Poniendo en entredicho la reorganización de recursos militares emprendida por el gobernador. AGI, Filipinas, 22, R.1, N.1. Testimonio de Cristóbal Márquez, Acapulco, 8 /08/1645.

116. OlLÉ, 2005 .

117. ANDRADE, 2007. 
Por su parte, la presencia hispánica en Formosa tampoco consiguió obstaculizar el comercio neerlandés de forma sensible, puesto que su presencia en la región tuvo una vertiente más terrestre que naval, no desarrollando una flota lo suficientemente poderosa como para hostigar y atacar las rutas y puertos de la VOC. Aunque de todos modos, sería la propia preeminencia mercantil de los Zheng en los estrechos la que condicionaría el trato neerlandés, reduciendo su preponderancia y desviando la actividad económica de la colonia hacia el desarrollo de una agricultura comercial. La cual, estuvo fundamentada principalmente, en el cultivo de arroz y caña de azúcar para su posterior venta en otros mercados y la obtención de tributos entre los campesinos chinos e indígenas de las plantaciones ${ }^{\mathrm{II} 8}$. Además, los intereses cruzados que este clan tenía con la Gobernación y la Compañía comercial, tampoco invitaban a desarrollar una agresiva activad en contra de este trato, pues cualquier ataque directo a los intereses del talasócrata podía devenir en sanciones directas o indirectas contra la Monarquía. Por lo que la presencia neerlandesa en el sur de Taiwán no acabó siendo un obstáculo para el comercio manileño, sino todo lo contrario, pues reforzó la inserción de esta isla en la red comercial asiática, propiciando la llegada de champanes chinos a Luzón directamente desde el sur de Formosa. De modo que, Sebastián Hurtado de Corcuera llegó incluso a afirmar que la presencia neerlandesa en Taiwán no había acabado suponiendo ningún problema para el trato filipino, ya que el flujo de mercancías chino se había mantenido inalterado o incluso se había incrementado desde i624. Aunque este escenario de auge comercial se contrapone a la situación vivida por Macao, que sí había encontrado numerosas dificultades en sus conexiones con Japón debido a la presencia de la VOC en los estrechos ${ }^{\mathrm{II}}$.

Por lo tanto, el viraje en las prioridades defensivas de la Gobernación no puede achacarse únicamente a las propias preferencias personales de Sebastián Hurtado de Corcuera, puesto que hacía varios años qué se había hecho patente un continuo descenso de la importancia de la frontera septentrional. El cual, era debido, al control de los Zheng de las aguas del mar de China, la introspección japonesa y a la dificultad para oponerse a las fuerzas neerlandesas desplegadas en Taiwán. Mientras que el fortalecimiento de la frontera meridional se había vuelto una necesidad, debido al elevado número de razzias piráticas que asolaron las Bisayas, a la obligación de afianzar la seguridad de las aguas interiores filipinas y a la consolidación de Batavia como centro neerlandés en el sureste asiático ${ }^{\text {I20 }}$. Por lo que, al voltearse la importancia de los frentes, las fortalezas taiwanesas disminuyeron su valor estratégico, pero siguieron requiriendo el envío de unos recursos que podrían ser utilizados en otras plazas que, en estos momentos, sí contaban con un papel

118. ANDRADE, 2006.

119. «Esto lo dessean los portugueses de Macán porque el enemigo les haze daño en el passo para Xapón, pero a la Corona de Castilla nada le embaraça ni le estorva en que los enemigos tengan allí puerto, pues los chinos no dejan de venir en 24 oras a las fuerças de vuestra majestad que están de esta otra parte, trayendo mercadurrías y mantenemientos necesarios». AGI, Filipinas 21, R.10, N.47. Carta de Sebastián Hurtado de Corcuera, Manila, 11/07/1636.

120. «Yo hallo señor, que vuestra magestad no tiene otra plaza de armas de mayor ynportançia en las indias que las yslas Filipinas, y para que se conozca si me fundo mal, considerese en que parte de las Indias a hecho la suya el enemigo, sino en la Xava, donde tiene Xacatra 300 leguas de aquí». AGI, Filipinas 8, R.1, N.16. Carta de Juan Niño de Távora, Manila, 3/07/1632. 
crucial para el mantenimiento de la presencia hispánica en Asia. Esta pérdida de interés por el limes norte, no solo afectó a Isla Hermosa, sino también a Nueva Segovia, que mantuvo un papel secundario durante el resto de siglo, ocupándose casi exclusivamente en resolver revueltas internas y en ejercer de centro para campañas de saqueo y expansión en los montes y valles cercanos.

\section{CONCLUSIONES}

En agosto de I642, una expedición neerlandesa compuesta únicamente por 690 hombres conquistó sin grandes esfuerzos San Salvador, venciendo a los escasos 330 soldados hispánicos que restaban en la isla ${ }^{121} \mathrm{y}$ acabando así con los escasos dieciséis años de presencia hispánica en Taiwán. Durante los cuales, la Monarquía no consiguió que su nueva posición se adaptara al entramado territorial preexistente. Puesto que no desarrolló unas facultades propias y diferenciadoras que no entraran en competencia directa con las que ya gozaban otros territorios o que ayudarán al resto de piezas de la Gobernación a funcionar de una manera conjunta. Así pues, no pudo convertirse en un entrepôt comercial destacado, pues no contaba con la tradición, población y anclaje en algunas de las principales rutas mercantiles de la región, como si lo hacían Manila, Macao o Goa. Mientras que su papel como mercado secundario para la obtención de mercancías chinas, acabó fracasando debido a la consolidación de los Zheng en los estrechos y a la revitalización que estos provocaron del comercio manileño. Tampoco consiguió ser un punto destacado en la lucha contra el auge de las Provincias Unidas en Asia. Puesto que la guerra contra esta potencia europea se concentró más en el archipiélago filipino, en las Molucas y en las aguas cercanas a las principales plazas lusas, convirtiendo la frontera norte de la Gobernación en un espacio cuasi inocuo y alejado de los principales frentes en disputa. Lo que provocó que la zona septentrional de Taiwán se disociara poco a poco del núcleo del conflicto y que las escaramuzas llevadas a cabo en este territorio no contaran con una gran transcendencia en la lucha contra las Provincias Unidas en el Pacífico. Pasando a ser un territorio completamente desencajado del resto de piezas del sistema defensivo filipino y que no contaba ni aportaba un valor económico o estratégico suficientemente elevado para justificar los gastos que generaba.

Del mismo modo, San Salvador tampoco pudo mantener un territorio dependiente, atraer las élites locales hacia la lealtad a la Monarquía, consolidar la hispanización dentro de su ámbito de influencia ni organizar un sólido sistema de tributos. Fracasando a la hora de conseguir un hinterland propio, que habría facilitado el acceso a un mayor número de recursos, haciendo a estos presidios menos dependientes de los socorros remitidos desde Manila. Esta escasa penetración en el territorio tampoco permitió buscar un sistema económico alternativo al comercio, como sí consiguió hacer el sur neerlandés con el desarrollo de una agricultura comercial basada en el azúcar de caña y el arroz. Por lo que al malograrse el proyecto

121. YU-TING, 2010. 
de utilizar la bahía de Jilong como catalizador de mercancías de Japón y Fujian para su posterior venta en Manila y encontrar numerosos problemas para obtener recursos y tributos de los indígenas, el sistema económico del Taiwán hispánico se desmoronó, convirtiéndose en un territorio militarizado completamente dependiente de los socorros manileños.

Por estos motivos, y aunque diversos historiadores como Johen Leddy Phelan ${ }^{122}$ o personajes contemporáneos como el gobernador Diego Fajardo ${ }^{123}$ hayan atribuido el fracaso de la experiencia hispánica en Taiwán a la reducción de recursos que se dio durante el gobierno de Sebastián Hurtado Corcuera en el frente norte, hay que tener en cuenta que, más que la causa, esta pudo ser la consecuencia de diversos movimientos regionales, que alteraron los planteamientos iníciales de los hispánicos y que dejaron a Taiwán sin atribuciones ni encaje dentro de la Gobernación más allá de expandir la fe católica y conservar el honor de las armas hispánicas. Por lo que ante esta tesitura, y ante el empuje neerlandés y de los Zheng en la región, era solo cuestión de tiempo que la Monarquía se viera forzada a abandonar la plaza, como así hizo con Zamboanga y Ternate en I662.

122. PHELAN, 1967

123. «Instó que se le ymbiase socorro, porque el enemigo le avía escrito que dejase la plaça y se la entregase, y el socorro que el governador le embió fue el ordinario que solía para el año de diez a doçe españoles y poco más pampangos». AGI, Filipinas, 22, R.1, N.1. Carta de Diego Fajardo, Manila, 15/08/1645. 


\section{BIBLIOGRAFÍA}

Alfonso Mola, Marina \& Martínez Shaw, Carlos (Eds.), El Galeón de Manila, Madrid, Aldeasa, 2003.

ANDrade, Tonio, «The Rise and Fall of Dutch Taiwan, I624-I662: Cooperative Colonization and the Statist Model of European Expansion», Journal of World History, I7:4 (Honolulu, 2006): 429-450.

Andrade, Tonio, How Taiwan Became China: Dutch, Spanish and Han Colonization in the Seventeenth Century, Nueva York, Columbia University Press, 2007.

BLussé, Leonard, «Minnan-jen or Cosmopolitan? The rise of Cheng Chinlung alias Nicolas Iquan», en Eduard B. Vermeer (ed.), Development and decline of Fukien Province in the $I 7^{\text {th }}$ and $I 8^{\text {th }}$ centuries, Leiden. Brill, I990: 245-264.

Buussé, Leonard, «No Boats to China. The Dutch East India Company and the Changing Pattern of the Sea Trade, I635-90», Modern Asian Studies, 30:I (Cambridge, I996):5I-76.

Bon DAR, Ku, «The Zheng Family and the Dutch in the Malay Archipelago: Competition and Conflict in the $17^{\text {th }}$ Century», Journal of Nusantara Studies, 32:2 (Kuala Terengganu, 20I8): 54-65.

Borao Mateo, José Eugenio, Spaniards in Taiwan, Taipei, SMC Publishing Inc, 200I

Borao Mateo, José Eugenio, «La colonia de japoneses en Manila en el marco de las relaciones de Filipinas y Japón en los siglos XVI y XVII», Cuadernos canela, I7 (Nagoya 2005): I-27.

Borao Mateo, José Eugenio, The Spanish Experience in Taiwan (I626-I642). The Baroque Ending of a Renaissance Endeavor, Hong Kong, Hong Kong University Press, 2009.

Busquets Alemany, Anna, «Los frailes de Koxinga», en Pedro San Ginés Aguilar (ed.), La investigación sobre Asia Pacífico en España, Granada, Universidad de Granada, 2007:393-42I.

CABEzAs, Antonio, El siglo ibérico del Japón: la presencia hispano-portuguesa en Japón, I543I643, Valladolid, Universidad de Valladolid, I995.

CARIOTI, Patrizia, «The Zhengs' maritime power in the international context of the $17^{\text {th }}$ century far eastern seas: The rise of a 'centralised piratical organisation' and its gradual development into an informal 'state'», Ming-Qing Yanjiu [Ming and Qing studies], 5:I (Leiden I996): 29-68.

CARIOti, Patrizia, Cina e Giappone sui mari nei secoli XVI e XVII, Nápoles, Edizioni Scientifiche Italiane, 2006.

CHANG, T'ien-Tsê, Sino-portuguese trade from I5I4 to I644, Leiden, Brill, I933.

Chen, Boyi, «Borders and Beyond: Contested Power and Discourse around Southeast Coastal China in the Sixteenth and Seventeenth Centuries», International Journal of Asian Studies, 15:I (Tokyo 2018): 85-116.

Chen, Wei-chung, War, Trade and Piracy in the China's Seas (I622-I683), Leiden, Brill, 2013.

CHen CHen, Fang, «Colonias españolas en Asia en el siglo XVII: relaciones entre Manila y San Salvador (norte de Taiwán)», en Albert Salvador Bernabeu Albert, Carmen Mena García y Emilio José Luque Azcona (Eds.), Filipinas y el Pacífico. Nuevas miradas, nuevas reflexiones, Sevilla, Editorial Universidad de Sevilla, 2016: 53-74.

Cocks, Richard, Diary of Richard Cocks, Cape-merchant in the English Factory in Japan, I6I5I622: with correspondence, Londres, Whithing and Co., I883.

CRAILSHEIM, Eberhard, «Las Filipinas, zona fronteriza. Algunas repercusiones de su función conectiva y separativa (I600-I762)», Aarón Grageda Bustamante (Ed.), Intercambios, 
actores, enfoques. Pasajes de la historia latinoamericana en una perspectiva global, Sonora, Universidad de Sonora, 20I4: I33-I52.

Díaz-Trechuelo Spínola, Lourdes, «Fortificaciones en las islas Filipinas (1565-180o)», en Puertos y fortificaciones de América Latina. Actas del seminario, Madrid, CEDEX, I985: 26I-280.

Flynn Dennis O. \& GiRÁldez, Arturo, «Silk for Silver: Manila-Macao trade in the $7^{\text {th }}$ Century», Philippine Studies, 44:I (Manila I996): 52-68.

GARcıA, Jose Manuel, «Relações históricas entre Macau e as Filipinas: uma perspectiva portuguesa», Anuario de estudios hispano-americanos, 65:2 (Sevilla 2008): pp.39-70.

Gil, Juan, Los chinos en Manila. Siglos XVI y XVII, Lisboa, CCCM, 201 I.

Giráldez, Arturo, The Age of Trade. The Manila Galleon and the Dawn of the Global Economy, Londres, Rowman \& Littefield, 2015.

GonzÁlez Alonso, Nuria, «Sebastián Hurtado de Corcuera: Gobernador de Panamá y de Filipinas», Anales de Museo de América, 20 (Madrid 2012): 199-218.

Gordon, Andrew, A Modern History of Japan: From Tokugawa Times to the Present, Oxford, Oxford University Press, 2003.

Herrera Reviriego, José Miguel, «Manila, organización y defensa en la frontera asiática del imperio de Felipe Il», en María Martínez Alcalde y José Javier Ruiz Ibáñez (eds.), Felipe II y Almazarrón: la construcción local de un Imperio global. Vivir, defender y sentir la frontera, Murcia, Editum, 2014: 203-218.

IACCARINO, Ubaldo, Comercio y diplomacia entre Japón y Filipinas en la era Keichō (I595-I6I5), Wiesbaden, Harrassowitz, 2017.

IACCARINO, Ubaldo, «El comercio chino en torno a Filipinas. Redes interregionales y conexiones transnacionales al final de la época Ming», Vegueta: Anuario de la Facultad de Geografía e Historia, 20 (Las Palmas de Gran Canaria, 2020): 217-238.

Iwao, Seiichi, «Li Tan. Chief of Chinese Residents at Hirado Japan in the Last Days of the Ming Dinasty», Memoirs of the research Department of the Toyo Bunko, I7 (Tokyo I958):27-83.

JасовS, Bruce J., «A History of Pre-Invasion Taiwan», Taiwan Historical Research, 23:4, (Taipei 20I6): I-38.

Kondo, Agustín Y., Japón. Evolución histórica de un pueblo (hasta 1650), Hondarrubia, Nerea, I999.

LовAто, Manuel: «As Filipinas e o Estado da Índia no Tempo dos Áustrias. Tensão, Convergêcia e Acomodação Entre os Imperios Ibéricos na Ásia do Sueste», en P. Cardim, M. Soares da Cunha y L. Freire Costas (Eds.), Portugal na Monarquia Espanhola. Dinâmicas de Integração e de Conflito, Lisboa, CHAM, 20I3: 40I-432.

Martín Onrubía, Miguel, «La ofensiva naval neerlandesa sobre Filipinas en el contexto de la Guerra de los Ochenta Años y su analogía con la llevada a cabo en los territorios americanos de la Monarquía Hispánica», en Marta María Manchado López y Miguel Luque Talaván (Eds.), Fronteras del mundo hispánico: Filipinas en el contexto de las regiones liminares novohispanas, Córdoba, Servicio de publicaciones de la universidad de Córdoba, 20II: $255-280$.

Newson, Linda A., Conquest and Pestilence in the Early Spanish Philippines, Honolulu, University of Hawaii Press, 2009.

Ollé, Manel, La empresa de China: de la armada invencible al Galeón de Manila, Barcelona, Acantilado, 2002. 
OlLÉ, Manel, «Comunidades mercantiles en conflicto en los estrechos de Taiwán (I624I684)», Revista de Historia Económica. Journal of Iberian and Latin American Economic History 23:I (Cambridge 2005): 275-298.

OlLÉ, Manel, «Manila in the Zheng Clan Maritime Networks», Reviews of Culture. International Edition 29 (Macao 2009): 9I-I03.

OllÉ, Manel, «Entre China y la Especiería. Castellanos y portugueses en Asia oriental» en Carlos Martínez Shaw \& José Antonio Martínez Torres (eds.), España y Portugal en el mundo (I58I-I668), Madrid, Polifemo, 2014: 369-390.

Phelan, Johen Leddy, The Hispanization of the Philippines. Spanish Aims and Filipino Responses. 1565-1700, Londres, The University of Wisconsin Press, 1967.

RoDAO, Florentino, Españoles en Siam (I540-I939). Una aportación al estudio de la presencia hispana en Asia, Madrid, CSIC, 1997.

Schurz, William Lytle, The Manila Galleon, Manila, Historical Conservation Society, 1985.

Stoos, Dirk Abraham, De Nederlanders in de Philippijnsche Wateren vóór I626, Ámsterdam, JH De Wit, I898.

Sousa (DE) PINTo, Paulo Jorge, «Manila, Macao and Chinese networks in South China Sea: adaptative strategies of cooperation and survival (sixteenth-to-seventeenthcenturies)», Anais de Historia de Além-Mar, I5 (Lisboa 2014): 79-100.

SouzA, George Bryan: The Survival of Empire. Portuguese Trade and Society and South China Sea (I630-I754), Cambridge, Cambridge University Press, I986.

Temminnck, Coenraad J., Las posesiones holandesas en el archipiélago de la India, Manila, Imprenta de los amigos del país, 1855.

Tremml-Werner, Birgit, Spain, China, and Japan in Manila, I571-I644, Ámsterdam, Amsterdam University Press, 2015.

WANG, Ming, «The Monetization of Silver in China: Ming China and Its Global Interactions», en María Dolores Elizalde y Wang Jianlang (eds.), China's Development From a Global Perspective, Newcastle, Cambridge Scholars Publishing, 20I7: 274-296

Yu-Ting, Lu, Taiwán. Historia, política e identidad, Barcelona, Bellaterra, 2010.

Yuste López, Carmen, El comercio de Nueva España con Filipinas, I590-1785, Ciudad de México, Instituto Nacional de Antropología e Historia, I984.

Yuste López, Carmen, «De la libre contratación a las restricciones de la permission. La Andadura de los comerciantes de México en los giros iníciales con Manila, I580-1610», en Salvador Bernabéu Albert y Carlos Martínez-Shaw (eds.), Un océano de seda y plata: el universo económico del Galeón de Manila, Sevilla, CSIC, 2013: 85-1o6. 


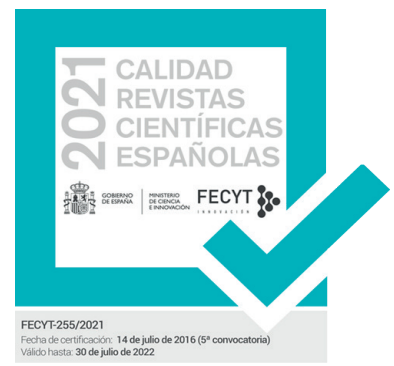

SERIE IV HISTORIA MODERNA

REVISTA DE LA FACULTAD DE GEOGRAFÍA E HISTORIA

AÑO 2021

ISSN: 1131-768X

E-ISSN 2340-1400

\section{4 \\ 西 ESPACIO, TIEMPO Y FORMA}

Monográfico - Special Issue: La política ultramarina de las monarquías ibéricas (circa 1700-1750): una historia de fracasos y éxitos relativos The Overseas Policy of the Iberian Monarchies (Circa 1700-1750): A History of Failures and Relative Successes

15 Roberto Quirós Rosado y MARIA FERnANDA BICALHO La política ultramarina de las monarquías ibéricas (circa 1700-1750): una historia de fracasos y éxitos relativos / The Overseas Policy of the Iberian Monarchies (Circa 1700-1750): A History of Failures and Relative Successes

\section{Guillaume Hanotin}

Defender negocios en tiempo de convulsión política: las elites mercantiles francesas durante la guerra de Sucesión española / Protecting Business in Time of Crisis: French Trademen during the War of Spanish Succession

\subsection{Maria Fernanda Bicalmo}

Ultramarino y el auge de los secretarios de Estado en Portugal durante la primera mitad del siglo XVIII / Sobre este modo de resolver e despachar os negócios. The decline of the Overseas Council and the Rise of the Secretaries of State in Portugal during the First Half of the $18^{\text {th }}$ Century

\section{9}

\section{VALENTINA FAVARò}

El fracaso de los proyectos de reforma en el virreinato peruano de principios

del siglo XVIII. Las propuestas de Carmine Nicola Caracciolo, príncipe de Santobuono the Eighteenth Century. The Proposals of Carmine Nicola Caracciolo, Prince of Santobuono

\section{7}

\section{ROBERTO QUIRÓS ROSADO}

Ecos de un mercantilismo truncado. El conde de Pinos Puente y la diplomacia comercial de Carlos VI en la corte de Lisboa (1723-1724) / Echoes of a Failed Mercantilism. The Count of Pinos Puente and the Commercial Diplomacy of Charles VI at the Court Of Lisbon (1723-1724)

\section{Junia Ferreira Furtado}

Portuguese America under Foreign Threat and the Creation of the Concept of uti possidetis in the First Half of the $18^{\text {th }}$ Century / La américa portuguesa bajo la amenaza exterior y la creación del concepto de uti possidetis en la primera mitad del siglo XVIII

\section{Miscelánea $\cdot$ Miscellany}

\section{José Antonio Mateos Royo}

con Cataluña / Trade Policy and Monetary Circulation in Aragon: Conflicts and Agreements with Catalonia (1535-1565)

\section{Fernando Altoé}

panegíricos atribuidos a la impresion. Un estudio de la trayectoria de dos the Trajectory of Two Panegyrics Attributed to João de Barros

\section{Francisco Velasco Hernández}

reino de Murcia (siglos XVI y XVII) / The Influence of the Berber Corsican on the Late Repopulation on the Coastal Area on the Kingdom of Murcia (XVI and XVII Centuries)

\section{José Antonio Martínez Martínez}

Criados, jornaleros y esclavos al servicio de la familia: la servidumbre de Serfdom of the Muñoz de Otálora in the $17^{\text {th }}$ Century

\section{Víctor Daniel Regalado González-Serna}

Benito de Medina a raíz de su ingreso en el cabildo catedral de Sevilla en 1669 / «Not a Single Good Portuguese». Accusations against Priest Alonso Benito de Medina when Entering the Cathedral Chapter of Seville in 1669

\section{José Herrera Reviriego}

organigrama comercial y militar de la Gober a tólo mitad del siglo XVII / "Only Time will Tell us»: The Role of Taiwan within the Commercial and Military Organization of the Philippine's Governoration during the First Half of the Seventeenth Century

\section{Manuel-Reyes García Hurtado}

de Rande, 1719-1733 / Vicissitudes of the Rescue Companies of the Sunken Ships in the Battle of Rande, 1719-1733

\subsection{Marcos de Miguel Muñoz}

Caballeros in 1769 


\section{4 ESPACIO, TIEMPO Y FORMA}

\section{Javier Tinoco Domínguez}

Tensiones sociopolíticas en el marco del catastro de Ensenada en Jerez de la Frontera: estudio de un conflicto institucional / Socio-Political Tensions within the Framework of Cadastre of Ensenada In Jerez de la Frontera: A Studying of an Institucional Conflict

\section{Pablo Fernández Albaladejo}

Fábulas de origen y gramática de nación en la España del siglo XVIII. A propósito de algunos trabajos de Francisco Martínez Marina / Origin's Fables and Grammar of Nation in the XVIII Century Spain. About some Works by Francisco Martínez Marina

\subsection{José María IÑURRITEgui Rodríguez}

Constitución increada: Francisco Martínez Marina y la crítica bíblica / Uncreated Constitution. Francisco Martínez Marina and Biblical Criticism

\subsection{David A. Abián Cubillo}

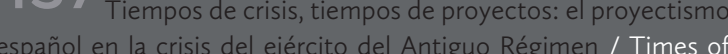
crisis, Times of Projects: The Spanish proyectismo during the Army's Crisis in the Ancient Regime

Taller de historiografía · Historiography Workshop

\section{Ensayos · Essays}

\subsection{ChrISTOPH ROSENMÜLLER}

«Tan peligrosas y feas conspiraciones»: la relación escrita por el embajador austriaco Christoph Migazzi en 1754 sobre la caída del marqués de la Ensenada / «Dangerous and Ugly Conspiracies». The Report of the Austrian Ambassador Christoph Migazzi on the Fall of the Marquis of la Ensenada in 1754

\subsection{Serge Gruzinskı}

Quelle histoire enseigner en 2021 ? / ¿Qué historia enseñar en 2021?

\subsection{Carlos Amate Pizarro}

Las relaciones hispano-chinas en el siglo XVI: síntesis e interpretación a la luz de la reciente historiografía / The Hispanic-chinese Relationship in the XVI Century: Synthesis and Interpretation in the Light of Recent Historiography

\section{Reseñas • Book Review}

521 Bolufer Peruga, Mónica, Arte y artificio de la vida en común. Los modelos de comportamiento y sus tensiones en el Siglo de las Luces, (Julio ArRoyo Vozmediano) 


\section{4 ESPACIO, TIEMPO Y FORMA}

525 Melón, Amando, Alejandro de Humboldt. Vida y obra (Carlos Martínez Shaw)

52 Commentary to Tatiana Seijas' review of The Atlantic World and the Manila Galleons: Circulation, Market, and Consumption of Asian Goods in the Spanish Empire (JosÉ LuIs GASCH TOMAS)

533 Braguier, Laurey, Servantes de dieu. Les beatas de la Couronne de Castille (1450-1600) (Manuela Águeda GARCÍA-GARRIDO)

539 Romeo, María CRuz; SAlomón, María Pilar; TABANERA, Nuria (eds.): Católicos, Reaccionarios y Nacionalistas. Política e identidad nacional en Europa y América Latina Contemporáneas (JAVIER M. Dos SANTOS)

54 Heredia López, Alfonso Jesús, El control de la corrupción en la Monarquía Hispánica. La Casa de la Contratación (1642-1660) (José Manuel Díaz Blanco)

17 Andújar Castillo, Francisco, El Atila de Madrid. La forja de un banquero en la crisis de la monarquía (1685-1715) (Aitor Díaz PAREdes)

551 Serrano Aviles, Javier y Mojarro, Jorge (eds.) Prada GonzALEZ, María (coord. de ilustraciones), En el archipiélago de la Especiería. España y Molucas en los siglos XVI y XVII (İ̃̃ıGo VALPUESTA VILLA)

555 Díaz Ceballos, Jorge, Poder compartido. Repúblicas urbanas, Monarquía y conversación en Castilla del Oro, 1508-1573 (JUAN SEbAstián Gómez GonZÁleZ)

51 Edelmayer, Friedrich, Massimiliano II, Filippo II I'Italia imperiale. II marchesato di Finale, i diritti imperiali e il «camino spagnolo» (RAFAEL VALLADARES)

56 Escribano-PÁEZ, José M., Juan Rena and the Frontiers of Spanish Empire, 1500-1540 (DAvid Martín Marcos)

56 ARnOLD, David, La Era de los Descubrimientos (1400-1600), Madrid, Alianza Editorial, 2021, 184 Pp., ISBN: 978-841362-172-2 (CARlos Amate Pizarro) 